\title{
Cholestatic Drug Induced Liver Injury: A Function of Bile Salt Export Pump Inhibition and Farnesoid X Receptor Antagonism
}

\author{
Jonathan P. Jackson, Kimberly M. Freeman, Robert L. St. Claire, III, \\ Chris B. Black, and Kenneth R. Brouwer
}

\begin{abstract}
Introduction: In vitro bile salt export pump (BSEP) inhibition alone does not accurately predict in vivo drug-induced liver injury in humans, suggesting that other mechanisms may be involved. Inhibition of BSEP has been shown to increase the hepatocellular concentrations of bile acids (BAs), and hepatobiliary disposition of BAs is tightly regulated by the farnesoid X receptor (FXR). Activation of FXR leads to decreased synthesis of BAs and increased expression of BA efflux transporters, BSEP, and organic solute and steroid transporter $(\mathrm{OST} \alpha / \beta)$. The link between BSEP inhibition and activation of the BA compensatory mechanism has not been clearly demonstrated.

Materials and Methods: Therefore, we utilized BSEP inhibitors, cyclosporine A (CsA) and troglitazone (Trog), to explore this "triggering" event using Transporter Certified ${ }^{\mathrm{TM}}$ sandwich-cultured human hepatocytes (SCHH). Results: Biliary excretion of glycine-cholic acid (GCA) as a percentage of total GCA accumulation was reduced in SCHH treated with either CsA or Trog. Within 12 hours, CsA treatment concomitantly increased intracellular concentrations (ICCs) of GCA and FGF19 mRNA content, an FXR-target gene. Separately, a synergistic 76.6fold increase of OST $\beta$ mRNA was observed following CsA and chenodeoxycholic acid co-exposure. In contrast, Trog exposure prevented the synergistic increase of OST $\beta$, a component of the basolateral BA efflux transporter, under the same conditions. Finally, BA toxicity potency was increased in SCHH exposed to Trog but not CsA. Discussion and Conclusions: Overall, these results suggested that BSEP inhibition activates the BA compensatory mechanism reducing ICCs of BAs. However, Trog possesses both BSEP inhibition and FXR antagonist properties blocking the activation of the compensatory mechanism resulting in BA-induced hepatotoxicity.
\end{abstract}

Key words: basolateral efflux, BSEP inhibition, cholestatic DILI, FXR antagonism, hepatic transport, in vitro model

\section{Introduction}

$\mathbf{T}$ HE LIVER PLAYS a central role in protecting and maintaining key metabolic functions and whole body homeostasis; in addition, it is one of the first organs exposed to orally administered drugs and is responsible for hepatic uptake, metabolism, and elimination of xenobiotics, As such, it is susceptible to drug induced liver injury (DILI), which remains one of the primary reasons for failures in drug development. $^{1-3}$

It is increasingly recognized that bile acids (BAs) play many critical roles in the signaling of key cellular pathways, including the regulation of hepatic lipid, glucose, and energy homeostasis, as well as inducing cell death through activation of death receptor pathways. ${ }^{4-6}$ Since BAs are toxic to the hepatocyte, disruption of BA homeostasis following drug exposure may lead to cholestatic DILI manifested as hepatocellular toxicity. Under normal conditions BAs are excreted primarily across the canalicular domain using the bile salt export pump (BSEP) with the basolateral efflux transporters MRP3/4 playing a minor role. ${ }^{7}$ Inhibition of BSEP could induce hepatotoxicity by causing intracellular concentrations (ICCs) of BAs to rise above a toxic threshold. ${ }^{8,9}$ Therefore, early cholestatic DILI screening efforts have focused on a compound's potential to inhibit BSEP transport using recombinant vesicles. 8,9 
Although BSEP is an important efflux mechanism for BA, it is not the only mechanism by which hepatic intracellular BA concentrations can be controlled. BAs act as signaling molecules to regulate their own ICC in hepatocytes by activation of the farnesoid $X$ receptor (FXR). ${ }^{10-12}$ Activation of FXR leads to the downregulation of CYP7A1, the rate limiting enzyme in the synthesis of BAs in the liver. ${ }^{13}$ FXR activation can also increase the expression of BSEP thereby increasing BA efflux into the bile. ${ }^{12}$ In addition to an increase in biliary efflux, BAs also have been shown to increase their own basolateral efflux through FXR mediated induction of the organic solute and steroid transporter $(\operatorname{OST} \alpha / \beta)$, which has recently been shown to be a major clearance pathway for intracellular BAs in the hepatocyte when ICCs of BA are increased. ${ }^{14-16}$ FXR activation serves as a compensatory mechanism responding to increases in the ICC of BAs to regulate both BA synthesis and efflux (e.g., biliary and basolateral transport).

BSEP inhibition potency is not always correlated with DILI (e.g., cyclosporine A (CsA); BSEP IC Bo $\left._{50}=0.5 \mu \mathrm{M}^{8}\right) .{ }^{17-19}$ In large clinical trials, initiation of CsA therapy was associated with only mild elevations in serum bilirubin levels, often without significant increases in serum alanine transaminase or alkaline phosphatase. ${ }^{20}$ Simple models such as recombinant transporter vesicles overlook the role that BA homeostatic mechanisms (e.g., the FXR compensatory mechanism) play in the prevention of BA hepatotoxicity. While single transporter data are useful in understanding compound liabilities, it is not predictive of bile acidinduced (e.g., cholestatic) hepatotoxicity. Accurate prediction of cholestatic liver toxicity requires that both inhibition events and compensatory mechanisms of the liver be taken into account.

To understand the relationship between BSEP inhibition and activation of the FXR compensatory mechanism, the functional impact (changes in BA ICCs and the activation of FXR target genes) following exposure to well-known BSEP inhibitors, CsA and troglitazone (Trog), was evaluated using sandwich-cultured Transporter Certified ${ }^{\mathrm{TM}}$ human primary hepatocytes. The principal aim of this study was to evaluate the hypothesis that inhibition of BSEP "triggers" a transient increase in the ICC of BAs resulting in the activation of FXR and initiating the compensatory mechanism to suppress synthesis and increase efflux, thereby preventing BA hepatotoxicity.

\section{Materials and Methods}

\section{Chemicals, hepatocytes, reagents}

HPLC grade methanol and acetonitrile were purchased from World Wide Medical Products (Bristol, PA). Transporter Certified human primary hepatocytes were obtained from Triangle Research Laboratories (RTP, NC) and ThermoFisher Scientific (Waltham, MA). Primary human hepatocytes were cultured with proprietary cell culture media formulations developed by Qualyst Transporter Solutions (QTS), now a part of ADME-Tox Division of BioIVT. QualGro $^{\mathrm{TM}}$ Seeding Medium and QualGro ${ }^{\mathrm{TM}}$ Culture Induction Medium supplemented with Matrigel (Corning, Tewksbury, MA) were from QTS (Durham, NC).

The base medium (Dulbecco's modified Eagle's medium) used by QTS and additional supplements, including fetal bovine serum, used for cell culture were from Gibco (Carlsbad, CA) and Corning (Tewksbury, MA). All quantitative realtime polymerase chain reaction (qRT-PCR) reagents were purchased from Thermo Fisher Scientific. Pierce BCA ${ }^{\mathrm{TM}}$ Protein Assays were also purchased from Thermo Fisher Scientific. Trog was purchased from Cayman Chemicals (Ann Arbor, MI). CsA and chenodeoxycholic acid (CDCA) were purchased from Sigma Aldrich (St. Louis, MO). DY268 was purchased from Tocris (Bristol, United Kingdom). Deuterated-TCA $\left(\mathrm{d}_{8}\right.$-TCA) was purchased from Martrex (Minnetonka, MN). Deoxycholic acid (DCA) was purchased from Santa Cruz Biotechnology (Dallas, TX), and all other BAs, including glycineDCA (GDCA), glycine-CDCA (GCDCA), and glycine-cholic acid (GCA), were purchased from Steraloids (Newport, RI).

\section{Preparation of sandwich-culture hepatocytes}

Sandwich-cultured human hepatocytes ( $\mathrm{SCHH})$ were established by thawing Transporter Certified cryopreserved hepatocytes (Table 1) according to the manufacturer's instructions. Once thawed, the cells were suspended in QualGro Seeding Medium, a QTS proprietary product, at a density of 0.8 million viable cells $/ \mathrm{mL}$ and seeded onto BioCoat ${ }^{\circledR} 24$-well $(\sim 0.4$ million cells/well) or 96-well $(\sim 0.05$ million cells/well $)$ cell culture plates purchased from Corning (Tewksbury, MA). Following the initial seeding, cells were allowed to attach for 2-4 hours, then rinsed and fed with $500 \mu \mathrm{L} /$ well warm $\left(37^{\circ} \mathrm{C}\right)$ QualGro Seeding Medium. After a culture time of

Table 1. Primary Hepatocytes Utilized Across Study

\begin{tabular}{|c|c|c|c|}
\hline Hepatocyte lot & $\operatorname{Sex}$ & Experiment & Figure \\
\hline DJJ & Male & Effects of CsA and troglitazone on BA biliary efflux & Figure $1 \mathrm{~A}-\mathrm{C}$ \\
\hline HUM4122C & Male & $\begin{array}{l}\text { Upregulation of basolateral efflux transporter expression } \\
\text { following BSEP inhibition }\end{array}$ & Figure 2 \\
\hline HUM4082B & Male & $\begin{array}{l}\text { Time course of CsA effects on GCA biliary efflux, } \\
\text { intracellular concentration, and FXR activation }\end{array}$ & Figure $3 \mathrm{~A}-\mathrm{C}$ \\
\hline DJJ & Male & $\begin{array}{l}\text { FXR antagonism reduces BA basolateral efflux } \\
\text { compensatory mechanism }\end{array}$ & Figure 4A, B \\
\hline FEA & Female & BA mediated hepatotoxicity assessment & Figure $5 \mathrm{~A}, \mathrm{~B}$ \\
\hline Hum16081 & Male & BA mediated hepatotoxicity assessment & Figure $5 \mathrm{C}$ \\
\hline FEA & Female & BA mediated hepatotoxicity assessment & Figure 6A, B \\
\hline FEA & Female & $\begin{array}{l}\text { Measuring FXR activation and ER stress under sensitization } \\
\text { conditions }\end{array}$ & $\begin{array}{l}\text { Figures } 7 \mathrm{~A}, \mathrm{~B} \\
\quad \text { and } 8 \mathrm{~A}, \mathrm{~B}\end{array}$ \\
\hline
\end{tabular}

BA, bile acid; BSEP, bile salt export pump; CsA, cyclosporine A; GCA, glycine-cholic acid; FXR, farnesoid X receptor. 
18-24 hours, the seeding medium was removed, and the cells were fed and overlaid with QualGro ${ }^{\mathrm{TM}}$ Induction Medium supplemented with $0.25 \mathrm{mg} / \mathrm{mL}$ Matrigel (Corning).

\section{Effects of CsA and Trog on BA biliary efflux}

The effects of CsA and Trog on the hepatobiliary disposition of BA were determined using SCHH as described above in 96well format and treated as follows. Stock solutions of CsA and Trog (1000× final concentration) were prepared in dimethyl sulfoxide (DMSO) and then diluted directly into QualGro Induction Medium day of assay to yield the desired final concentrations. Hepatocytes were treated with either CsA or Trog at $1,5,10,25,50$, and $100 \mu \mathrm{M}$ for 2 hours on day 5 of culture. Following the 2-hour exposure period, the cultures were rinsed, and a disposition study with $\mathrm{d}_{8}$-TCA was performed using BCLEAR $^{\circledR}$ technology as previously described. ${ }^{21,22}$ SCHH, in parallel cultures, were washed twice with Plus $(+)$ buffer (buffer containing $\mathrm{Ca}^{++} / \mathrm{Mg}^{++}$) or Minus (-) buffer (buffer without $\left.\mathrm{Ca}^{++} / \mathrm{Mg}^{++}\right)$. The wash solutions were removed and replaced with fresh Plus (+) or Minus (-) buffer and incubated for 10 minutes at $37^{\circ} \mathrm{C}$ to modulate tight junctions. ${ }^{21,22}$ Following the incubation, the wash solution was removed, and the hepatocytes were then washed thrice with ice-cold Plus (+) Buffer. The plates were frozen at $-80^{\circ} \mathrm{C}$ until processed for bioanalysis to determine protein content and disposition of $\mathrm{d}_{8}$-TCA. The Biliary Excretion Index (BEI), biliary clearance $\left(\mathrm{Cl}_{\text {Biliary }}\right)$, and total accumulation were determined as shown in the Data Analysis section. Protein content was determined using Pierce ${ }^{\mathrm{TM}}$ BCA Protein Assay Kit (Thermo Fisher Scientific, Waltham, MA) following manufacturer's instructions.

\section{Upregulation of basolateral efflux transporter expression following BSEP inhibition}

The BA basolateral efflux transporter, $\mathrm{OST} \alpha / \beta$, is regulated by an FXR-dependent mechanism and may function as a "safety valve" to decrease the ICC of BAs in the hepatocyte when they are elevated. ${ }^{14-16} \mathrm{SCHH}$ were prepared and treated with CsA (1, 10 , and $20 \mu \mathrm{M})$, Trog $(10,50$, and $100 \mu \mathrm{M})$, CDCA $(30 \mu \mathrm{M})$, CsA $(1,10$, and $20 \mu \mathrm{M})+\mathrm{CDCA}(30 \mu \mathrm{M})$, and Trog $(10,50$, $100 \mu \mathrm{M})+\mathrm{CDCA}(30 \mu \mathrm{M})$. Stock solutions were prepared as previously described and diluted $(1000 \times)$ directly into QualGro Induction Medium daily to achieve the desired final concentrations. SCHH were established as described above in 24-well format and were treated for 72 hours with daily media changes. Following the designated exposure period, $\mathrm{SCHH}$ were washed once with one volume of HBSS and lysed by addition of $0.3 \mathrm{~mL}$ of Qiagen RLT Buffer supplemented with $\beta$-mercaptoethanol and frozen at $-80^{\circ} \mathrm{C}$ until processed for total mRNA isolation and subsequent qRT-PCR analysis of FXR target genes, FGF19, and OST $\beta,{ }^{15,16,23,24}$ as described below.

\section{Time course of CsA effects on GCA biliary efflux, ICC, and FXR activation}

The biliary efflux, ICC of endogenous GCA, and FXR activation in $\mathrm{SCHH}$ exposed to $\mathrm{CsA}(10 \mu \mathrm{M})$ were determined at multiple time points up to 12 hours. Stock solutions were prepared as previously described. SCHH were established as described above in 24-well format. Once established the hepatocytes were treated with CsA $(10 \mu \mathrm{M})$ for $10,60,120,240$, and 720 minutes. The plates were frozen at $-80^{\circ} \mathrm{C}$ until pro- cessed for bioanalysis to determine protein content and disposition of endogenous GCA. Endogenous GCA was quantitated as described below, and the hepatobiliary disposition of GCA was determined using B-CLEAR technology as previously described following the designated exposure period. ${ }^{21,22}$ In parallel plates, hepatocytes were harvested for total mRNA isolation to evaluate FXR activation by assessing the mRNA content of FGF19 and OST $\beta$, sensitive FXR target genes ${ }^{15,16,23,24}$ as described below.

\section{Evaluation of FXR activation}

FXR activation was determined in SCHH after treatment with potent BSEP inhibitors. Trog has been reported to modulate FXR. Kaimal et al. suggested that Trog was a weak FXR agonist at low concentrations, but could antagonize FXR activation at higher concentrations. ${ }^{25}$ DY268 has been shown to be a potent FXR antagonist. ${ }^{26} \mathrm{SCHH}$ were prepared and treated with CsA $(10 \mu \mathrm{M})$, or CDCA $(30 \mu \mathrm{M})$ alone, CsA $(10 \mu \mathrm{M})+$ CDCA $(30 \mu \mathrm{M})$, Trog $(100 \mu \mathrm{M})+\operatorname{CsA}(10 \mu \mathrm{M})+\operatorname{CDCA}(30 \mu \mathrm{M})$, or DY268 $(5 \mu \mathrm{M})+$ CsA $(10 \mu \mathrm{M})+$ CDCA $(30 \mu \mathrm{M})$. Stock solutions were prepared as previously described. SCHH (24-well format) were treated on day 4 of culture for 24 hours in triplicate as described above. Following the designated exposure period, SCHH were washed once with one volume of HBSS and prepared for mRNA analysis as described below.

\section{$B A$ mediated hepatotoxicity assessment}

SCHH were established as previously described in 96-well format. On day 4 of culture, SCHH were exposed to CsA $(10 \mu \mathrm{M})$ or Trog $(100 \mu \mathrm{M})$ for 24 hours. Compound stocks $(1000 \times)$ were diluted directly into media alone or media containing a fixed concentration of free fatty acids (FFAs) and varying concentrations of pooled BAs up to a total BA concentration of $5 \mathrm{mM}$. The pooled BA contained a physiological mixture of the four most abundant $\mathrm{BA}$ in human serum (GCDCA, GCA, DCA, and GDCA) formulated at in vivo relevant ratios (1.0 GDCA: 1.0 DCA: 2.0 GCA: 4.5 GCDCA) as reported in Ogimura et al. These ratios remained constant as the total bile acid concentration was increased. ${ }^{27}$

In a parallel experiment, the effect of increasing FFA concentrations was evaluated. On day 4 of culture, SCHH were exposed to CsA $(10 \mu \mathrm{M})$ or Trog $(100 \mu \mathrm{M})$ for 24 hours. Compound stocks $(1000 \times)$ were diluted directly into media alone or media containing a fixed concentration of pooled BA $(250 \mu \mathrm{M})$ and varying concentrations of FFAs (1:2 palmitate:oleate) from $0.1 \mathrm{mM}$ to $1.0 \mathrm{mM}$. The FFA exposure in combination with BA was evaluated since lipid loading of hepatocytes has been reported to sensitize hepatocytes to BA-induced cytotoxicity. ${ }^{28}$ Lipid accumulation and BA accumulation (e.g., cholestasis) activate similar death pathways controlling programmed cell death (e.g., apoptosis/necroptosis). ${ }^{6,29,30}$ Following the exposure period, cellular ATP was determined using CellTiter-Glo ${ }^{\mathrm{TM}}$ Luminescent Cell Viability Assay from Promega (Madison, WI). Each treatment group was evaluated in triplicate wells in Transporter Certified cryopreserved human hepatocytes.

\section{Measuring FXR activation and ER stress under sensitization conditions}

To assess FXR activation and ER stress under sensitization conditions (e.g., $250 \mu \mathrm{M}$ BA pool and $1 \mathrm{mM}$ FFA), 
SCHH were established in 24-well format as previously described. On day 4 of culture, $\mathrm{SCHH}$ were exposed to $\mathrm{CsA}$ $(10 \mu \mathrm{M})$, Trog $(100 \mu \mathrm{M})$, or DY268 $(5 \mu \mathrm{M})$ for 12 hours. Compound stocks $(1000 \times)$ were diluted directly into media alone, media containing a fixed concentration of BA $(250 \mu \mathrm{M}$ BA pool $)$, media containing a fixed concentration of FFAs (1 mM; 1:2 palmitate:oleate), and media containing a fixed concentration of FFAs ( $1 \mathrm{mM}$; 1:2 palmitate:oleate) and BAs $(250 \mu \mathrm{M}$ BA pool). Following the designated exposure period, $\mathrm{SCHH}$ were washed once with one volume of HBSS and processed for total mRNA isolation and subsequent qRT-PCR analysis of FXR target genes, FGF19 and OST $\beta$, and ER stress biomarker, CCAAT/enhancer-binding protein $(\mathrm{C} / \mathrm{EBP})$ homologous protein $(\mathrm{CHOP})^{29-31}$ as described below. In parallel, lactate dehydrogenase (LDH) leakage was evaluated in cell culture media from same hepatocyte cultures following 12 hours of exposure to drug treatment. LDH leakage was determined using CytoTox-ONE ${ }^{\mathrm{TM}}$ Homogeneous Membrane Integrity Assay from Promega (Madison, WI). Each treatment group was evaluated in triplicate wells in Transporter Certified cryopreserved hepatocytes.

\section{Total RNA isolation and $q R T-P C R$}

To evaluate treatment effects on FXR activation and ER stress in SCHH, mRNA content of FXR target genes, OST $\beta$ or FGF 19, ${ }^{15,16,23,24}$ and ER stress biomarker, $C H O P,{ }^{29-31}$ was determined. Following exposure period with specified treatment, total mRNA was extracted using a QIAGEN RNeasy ${ }^{\circledR}$ Kit (Qiagen, Hilden, Germany), according to the manufacturer's instructions. Before extraction the cells were lysed by adding a $0.3 \mathrm{~mL}$ aliquot of Qiagen RLT lysis buffer (supplemented with $\beta$-mercaptoethanol) to each plate. The plates were then frozen at $-80^{\circ} \mathrm{C}$ to lyse the cells and then thawed to continue the RNA isolation procedure. Total RNA was isolated from each treatment group. The RNA isolated from three individual wells within a group was pooled. The isolated RNA was quantified using the Quant-iT RiboGreen ${ }^{\circledR}$ RNA Assay Kit (Thermo Fisher Scientific) according to the manufacturer's instructions. Pooled total RNA samples were used to prepare cDNA using $500 \mathrm{ng}$ in the High Capacity cDNA Archive Kit (Thermo Fisher Scientific) according to the manufacturer's instructions. Changes in gene expression were measured by analyzing the cDNA prepared from each treatment group with gene-specific TaqMan $^{\circledR}$ assays (Thermo Fisher Scientific) for OST $\beta$ (Assay\# Hs01057182_m1), FGF19 (Assay\# Hs00192780_m1), and CHOP (Hs00358796_g1). Glyceraldehyde 3-phosphate dehydrogenase (GAPDH; Assay\# Hs99999905_m1) was used as the endogenous housekeeping gene to normalize each sample. Polymerase chain reaction (PCR) was performed on a ViiA ${ }^{\mathrm{TM}} 7$ system Real-Time PCR System (Thermo Fisher Scientific) in relative quantification mode for 45 amplification cycles. Standard conditions for TaqMan-based assays were used. The determination of threshold cycles $(\mathrm{Ct})$ was determined by the Vii7 system software for all target genes (OST $\beta, F G F 19, C H O P)$ and endogenous control $(G A P D H)$ genes. Relative-fold mRNA content was determined for each treatment group relative to the endogenous control gene expression and the calibrator, DMSO vehicle control using the ViiA 7 system software. Confidence intervals of $95 \%$ were calculated for each target gene relative quantitation (RQ) mean by the ViiA 7 system software.

\section{Bioanalysis of $B A$}

GCA or $\mathrm{d}_{8}$-TCA was extracted from cell lysates derived from the individual wells of 24-well cell culture plates. BA extraction was initiated by adding a $500 \mu \mathrm{L}$ aliquot of lysis solution (70:30 methanol:water [v:v] containing $25 \mathrm{nM}$ of $\mathrm{d}_{5}$-TCA as an internal standard) to each well. Cell lysis was performed by allowing the plates to shake for at least $15 \mathrm{~min}$ utes at room temperature. The cell lysates were then transferred to Whatman 96-well UNIFILTER $25 \mu \mathrm{m}$ MBPP/ $0.45 \mu \mathrm{m}$ PP filter plate (Whatman, 7770-0062) and stacked on a 96-well deep well plate. Filtration of the lysates was accomplished by centrifugation and collection of the filtrate in the deep well plate ( $2390 \mathrm{rcf}$ for 2 minutes). The filtrate was then concentrated by first evaporating the samples to dryness under Nitrogen and then reconstituting with 120 or $150 \mu \mathrm{L}$ of sample diluent (60:40 methanol:water containing $4 \mathrm{mM}$ ammonium acetate). The samples were mixed for 10 minutes on a plate shaker at room temperature. To prepare the reconstituted samples for LC-MS/MS analysis, they were transferred to a Millipore 0.45 um filter plate (Millipore, MSHVN45) and filtered into a Costar 3957 plate by centrifugation (2390 rcf for 2 minutes) and then sealed with a silicone capmat for analysis.

LC-MS/MS was performed using a Thermo Electron TSQ ${ }^{\circledR}$ Quantum Discovery MAX ${ }^{\mathrm{TM}}$ (Waltham, MA) with an Ion Max ESI source operated in negative electrospray ionization mode. Chromatographic separation of endogenous BA and their deuterated counterparts (for use as analytical standards) was achieved using a Shimadzu binary HPLC system with LC-10ADvp pumps (Columbia, MD) equipped with a Thermo Scientific Hypersil GOLD ${ }^{\mathrm{TM}} 100 \times 1.0 \mathrm{~mm}, 3 \mu \mathrm{m}$ with matching guard, and precolumn filter (Bellefonte, PA), using a linear gradient of $45 \%-100 \% \mathrm{~B}$, at a flow rate of $0.05 \mathrm{~mL} / \mathrm{minute}$, with mobile phase A as $20 \%$ methanol with $0.25 \mathrm{mM}$ ammonium acetate and mobile phase $\mathrm{B}$ as $80 \%$ methanol with $0.25 \mathrm{mM}$ ammonium acetate, both at native $\mathrm{pH}$.

\section{Data analysis}

All calculations were performed using Microsoft Excel, 2010 unless otherwise stated. Statistical analyses were performed using GraphPad Prism Software Version 7.0 (La Jolla, CA), and $p$-values were defined in the figure legends where applicable. Hepatobiliary disposition results, including BEI, $\mathrm{Cl}_{\text {Biliary }}$, and total accumulation of $\mathrm{d}_{8}$-TCA, were analyzed using a two-way analysis of variance (ANOVA) followed by a Dunnet's multiple comparison test. Hepatobiliary disposition results, BEI and ICC, of endogenous GCA following a 12-hour time course exposure to CsA, were assessed using a two-way ANOVA followed by a Sidak's multiple comparison test. Changes in gene expression were determined to be statistical significant if the $95 \%$ confidence intervals, calculated by the ViiA 7 system software, failed to overlap across treatment groups. Nonlinear regression $\quad\left(\mathrm{Y}=\right.$ Bottom $+($ Top-Bottom $) /\left(1+10^{\wedge}((\operatorname{LogEC} 50-\right.$ $\mathrm{X}) \times$ HillSlope) $)$ ) of ATP content versus BA or FFA concentration (Log) was performed using GraphPad Prism Software Version 7.0 (La Jolla) to estimate the concentration reducing cell viability by $50 \%$ (e.g., $\mathrm{TC}_{50}$ ). The $\mathrm{TC}_{50}$ parameter was utilized to compare changes in BA or FFA potency in the presence or absence of CsA or Trog. Statistical significance of ATP content and LDH leakage results was evaluated using a one-way ANOVA followed by a Dunnet's multiple comparison test. 
To quantitate BA biliary efflux, the BEI was determined as previously described. ${ }^{21,22}$ Briefly, BA mass values measured in hepatocyte lysates were normalized to the total cellular protein (mg) content per well. Total accumulation of BA is defined as the mass of the BA in the hepatocyte plus the bile pocket and was determined in cells incubated with Plus (+) buffer. Cellular accumulation of BA is defined as the mass of BA in the hepatocyte only and was determined in cells incubated with Minus (-) buffer. The bile accumulation was calculated by subtracting the cellular accumulation (no bile pockets) from the total accumulation (presence of bile pockets). The BEI represents the percent of total mass taken up excreted into the bile and was calculated (equation 1) by dividing the bile accumulation by the total accumulation and multiplying by 100 .

Equation 1:

$$
\text { BEI }=100 \times \frac{\text { Bile Accumulation }}{\text { Total Accumulation Plus }(+) \text { Buffer }}
$$

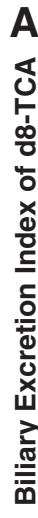

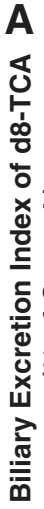

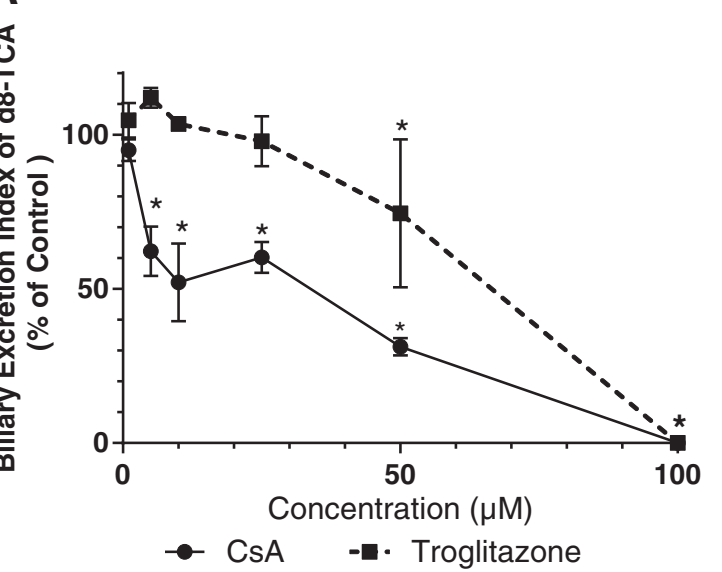

B
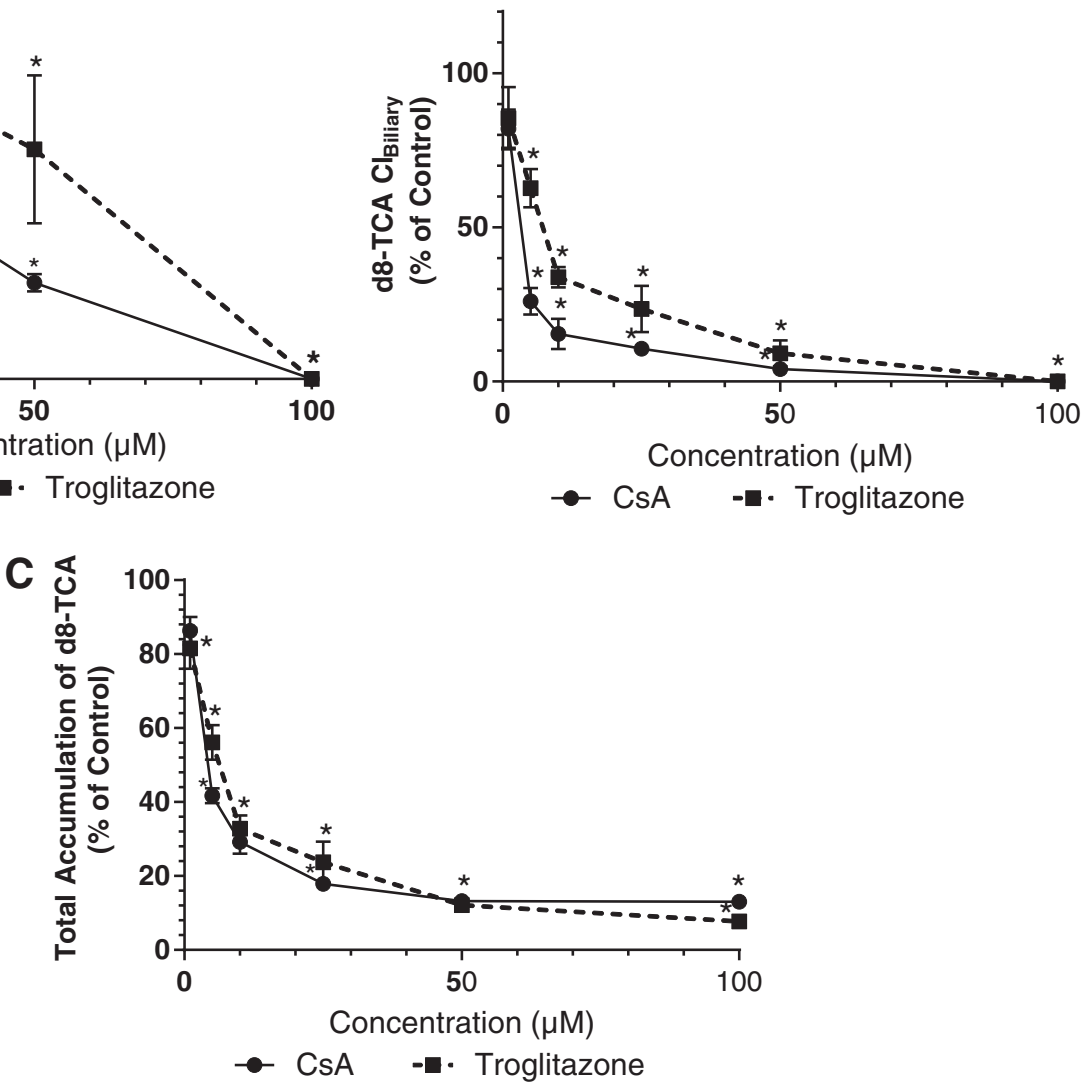

FIG. 1. (A-C) Concentration dependent effects of CsA and Trog on the hepatobiliary disposition of $\mathrm{d}_{8}$-TCA. Following exposure to well-known BSEP inhibitors, the (A) biliary excretion (BEI), (B) biliary clearance, and (C) total accumulation of $\mathrm{d}_{8}$-TCA were evaluated in SCHH utilizing B-CLEAR ${ }^{\circledR}$ Technology. SCHH were established and treated as described under Materials and Methods. Following a 24-hour exposure period to various concentrations of CsA and Trog, hepatocytes were exposed to $\mathrm{d}_{8}$-TCA for 10 minutes. The cell lysates were processed as described, and $\mathrm{d}_{8}$-TCA concentration was measured by LC/MS/MS. Mean and SD of triplicate wells are reported. "*” Denotes statistical significant difference compared to solvent control, (A) $p$-value $\leq 0.001$; (B) $p$-value $\leq 0.0004$; (C) $p$-value $\leq 0.03$. BEI, Biliary Excretion Index; BSEP, bile salt export pump; CsA, cyclosporine A; Trog, troglitazone; $\mathrm{SCHH}$, sandwich-cultured human hepatocytes. 


\section{Results}

\section{CsA and Trog inhibit biliary excretion of $B A$}

Following a 2 hour exposure to the BSEP inhibitors, CsA and Trog, the BEI of $\mathrm{d}_{8}$-TCA decreased in a concentrationdependent manner (Fig. 1A). CsA was a more potent inhibitor of $\mathrm{d}_{8}$-TCA biliary excretion at all concentrations. Both compounds completely inhibited the biliary excretion of $\mathrm{d}_{8}$-TCA at $100 \mu \mathrm{M}$. The $\mathrm{Cl}_{\text {Biliary }}$ and the total accumulation of $\mathrm{d}_{8}$-TCA also decreased in a concentration-dependent manner following exposure to CsA and Trog (Fig. 1B, C). At $100 \mu \mathrm{M}, \mathrm{CsA}$ and Trog completely inhibited $\mathrm{Cl}_{\text {Biliary }}$, and the total accumulation decreased to $<20 \%$ of control. These results were consistent with past published results on the effect of CsA and Trog in SCHH. ${ }^{33,34}$

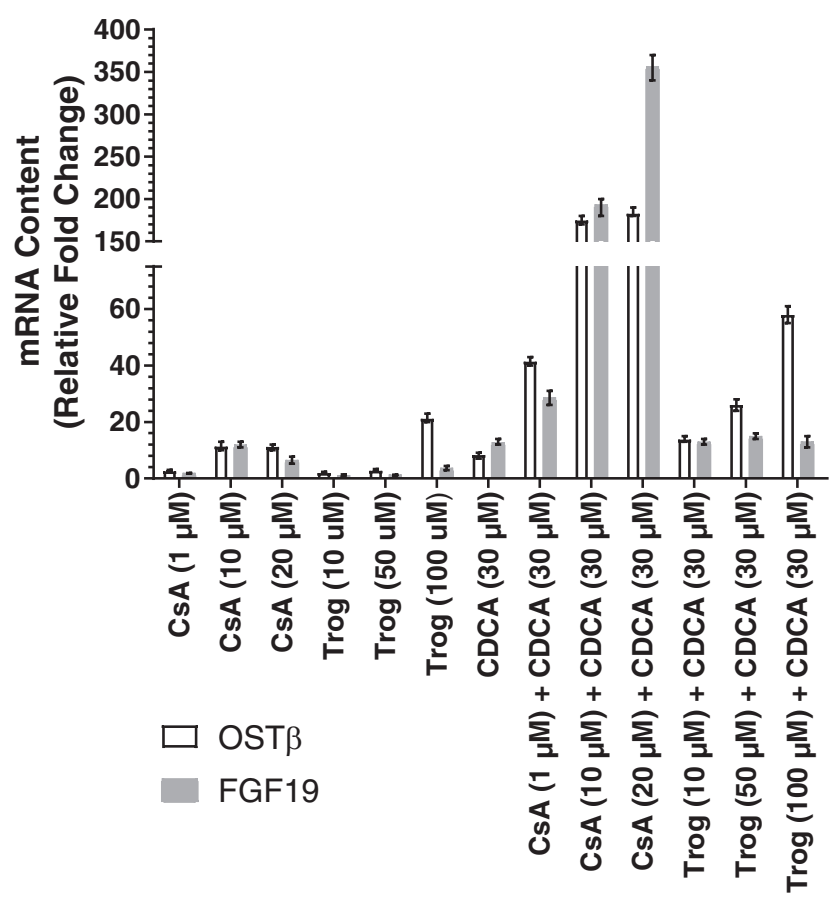

FIG. 2. The basolateral efflux transporter $O S T \beta$ is upregulated by BSEP inhibition in SCHH. The expression of FXR target genes, OST $\beta$ and FGF 19, was evaluated in SCHH following treatment with CsA (BSEP inhibitor), CDCA (FXR agonist), and CsA + CDCA. SCHH were established and treated as described under Materials and Methods. After 72 hours, the cells were harvested and total RNA extracted for qRT-PCR. The BSEP inhibitor CsA (10 and $20 \mu \mathrm{M})$ increased OST $\beta$ and FGF19 mRNA content. Similarly, the FXR agonist CDCA $(30 \mu \mathrm{M})$ increased $O S T \beta$ and $F G F 19$ mRNA content. A synergistic increase in OST $\beta$ and FGF19 mRNA content was observed in SCHH co-treated with CsA $(1,10,20 \mu \mathrm{M})$ and CDCA $(30 \mu \mathrm{M})$. Coadministration of Trog $(10,50,100 \mu \mathrm{M})$ and CDCA $(30 \mu \mathrm{M})$ resulted in lower dose-dependent increases in OST $\beta$ and smaller increases in FGF19 mRNA content. Values represent the RQ mean, and error bars represent $95 \%$ confidence intervals. CDCA, chenodeoxycholic acid; FXR, farnesoid X receptor; qRT-PCR, quantitative real-time polymerase chain reaction; $R Q$, relative quantitation.

\section{Upregulation of basolateral efflux transporter expression following BSEP inhibition}

The FXR agonist, CDCA $(30 \mu \mathrm{M})$, induced both FGF19 and OST $\beta$ mRNA content in SCHH following 72 hours of treatment consistent with published results (Fig. 2). ${ }^{15,16,24}$ Following treatment of $\mathrm{SCHH}$ with increasing concentrations of CsA $(1,10,20 \mu \mathrm{M})$, increases in FGF19 and OST $\beta$ mRNA content were observed up to $10 \mu \mathrm{M}$ and ranged from 1.78- to 11.8-fold greater than solvent control for FGF19 and 2.68- to 11.4-fold greater than solvent control for OST $\beta$. The increases in FGF 19 and OST $\beta$ following treatment with CsA were consistent with activation of the bile acid sensing receptor, FXR. Coadministration of CsA and CDCA resulted in dose-dependent and synergistic increases of 28.5- to 356-fold and 41.5- to 183-fold in FGF19 and OST $\beta$ mRNA content in SCHH, respectively (Fig. 2). Coadministration of Trog (10, 50, $100 \mu \mathrm{M})$, a well-established BSEP inhibitor, and CDCA $(30 \mu \mathrm{M})$, resulted in lower dose-dependent increases in OST $\beta$ and much smaller increases in FGF19 mRNA content in SCHH (Fig. 2). Increases in OST $\beta$ and FGF 19 mRNA content were $68 \%$ and $96 \%$ lower with Trog $(100 \mu \mathrm{M})$ and CDCA $(30 \mu \mathrm{M})$ co-treatment than CsA $(10 \mu \mathrm{M})$ and CDCA $(30 \mu \mathrm{M})$ co-treatment.

\section{Time course of the BA compensatory mechanism in $\mathrm{SCHH}$}

Compared to the solvent control, exposure to CsA $(10 \mu \mathrm{M})$ decreased the biliary efflux (BEI) of endogenous GCA in a time-dependent manner with maximum inhibition occurring within 4 hours of exposure (Fig. 3A). In the same plate, concomitant time-dependent increases in the ICC of GCA were observed and achieved statistical significance following 10 minutes of exposure to CsA (Fig. 3B). The GCA ICC was highest $(56.4 \mu \mathrm{M})$ following 12 hours of CsA exposure and represented 8.18-fold increase relative to the solvent control. These results directly link inhibition of canalicular BA efflux to increases in the ICCs of BA. Concomitant time-dependent increases in FGF19 mRNA content were observed over the same time frame as the observed increases in GCA ICCs, reaching a maximum response (3.61-fold greater than solvent control) following 12 hours of CsA exposure (Fig. 3C). However, no marked changes of OST $\beta$ mRNA content were observed across the 12-hour CsA exposure period. FGF19 mRNA content results support the conclusion that BSEP inhibition increases the ICC of BA, which then leads to activation of FXR.

\section{FXR regulates $B A$ basolateral efflux compensatory mechanism}

Co-treatment with CsA and CDCA resulted in a synergistic increase in FGF19 and OST $\beta$ mRNA content of 60.8 -fold and 76.6-fold greater than solvent control, respectively (Fig. 4A). However, when Trog $(100 \mu \mathrm{M})$ or DY268 $(5 \mu \mathrm{M})$, a potent FXR antagonist, ${ }^{26}$ was coincubated with CsA and CDCA, the response of FGF19 gene expression was decreased by $70 \%$ and $91 \%$, respectively. Likewise, OST $\beta$ gene expression following treatment with Trog $(100 \mu \mathrm{M})$ or DY268 $(5 \mu \mathrm{M})$ in the presence of CsA and CDCA was decreased by $52 \%$ and $92 \%$, respectively. These results were consistent with antagonism of FXR. There were no statistically significant (Dunnett's; $p$-value $\geq 0.05$ ) decreases in cell viability as measured 


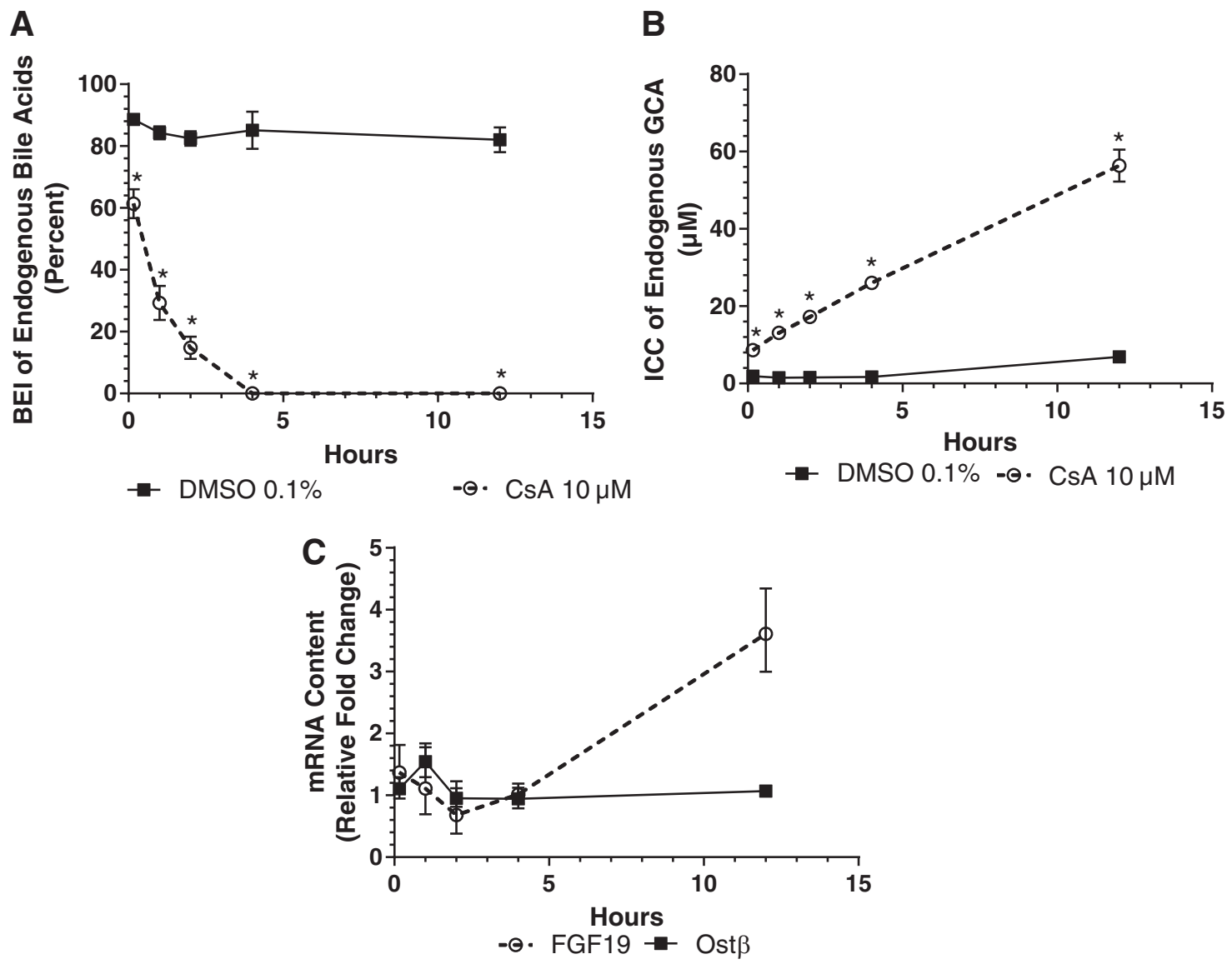

FIG. 3. (A-C) Effects of CsA on GCA Biliary Elimination, GCA ICC, and Induction of the FXR target genes. The kinetics of the hepatic bile acid homeostasis mechanism in SCHH was evaluated following 0.16, 1, 2, 4, and 12 hours of exposure to CsA $(10 \mu \mathrm{M})$. SCHH were established and treated as described under Materials and Methods. (A) Biliary elimination of GCA was reduced in a time-dependent manner reaching statistical significance by 10 minutes of exposure to CsA. (B) Concomitant time-dependent increases in the ICC of GCA were observed reaching statistical significance within 10 minutes of exposure to CsA. (C) Concomitant time-dependent increases in FGF19, an FXR target gene, mRNA content were also observed. BEI and ICC values represent the mean and SD of triplicate wells. mRNA content values represent the RQ mean, and error bars represent $95 \%$ confidence intervals. "*” Denotes statistical significant difference compared to solvent control, (A) $p$-value $\leq 0.0001$; (B) $p$-value $\leq 0.0001$. DMSO, dimethyl sulfoxide; GCA, glycine-cholic acid; ICC, intracellular concentration.

by ATP when any of the compounds were administered alone or in combination (Fig. 4B). Overall, these results suggested that disruption of FXR activation reduces the BA basolateral efflux compensatory mechanism in SCHH.

\section{Assessing BA-induced hepatotoxicity}

Increased exposure to BAs in the absence of CsA, Trog, or FFAs decreased the hepatocyte viability in a dose-dependent manner (Fig. 5A, B). Addition of $1 \mathrm{mM}$ FFA to the BA pool titration resulted in a slight $(<10 \%)$ additional decrease in cell viability (Fig. 5A, B). Addition of CsA $(10 \mu \mathrm{M})$ to the BA pool titration in the absence or presence of FFAs, had no effect on the cell viability (Fig. 5A, Table 2). Addition of Trog $(100 \mu \mathrm{M})$ to the BA pool titration in the absence of FFAs had a small effect on the cell viability (Fig. 5B, Table 2) decreasing the $\mathrm{TC}_{50}$ from 0.95 to $0.66 \mathrm{mM}$. However, increasing the exposure concentration of BAs in the presence of a fixed concentration of Trog $(100 \mu \mathrm{M})$ and
FFAs $(1 \mathrm{mM})$ reduced the cell viability to less than $1 \%$ of control at the lowest BA concentration. In a second donor, increased exposure to $\mathrm{BA}$ in the absence or presence of $1 \mathrm{mM}$ FFA resulted in a dose-dependent decrease in hepatocyte viability with similar estimated $\mathrm{TC}_{50}$ values (Fig. $5 \mathrm{C}$, Table 2). Increasing the BA pool concentration in the presence of $\operatorname{Trog}(100 \mu \mathrm{M})$ in the absence of FFAs decreased the $\mathrm{TC}_{50} 2.74$-fold from 1.4 to $0.51 \mathrm{mM}$ (Fig. 5C, Table 2) in this donor. In the presence of FFA, Trog treatment reduced the $\mathrm{TC}_{50}>10.4$-fold from 1.3 to $0.125 \mathrm{mM}$ (Fig. 5C, Table 2) in this preparation of hepatocytes.

Increasing the FFA concentration in the absence of CsA, Trog, or a BA pool (Fig. 6A, B, Table 3) resulted in a slight decrease in viability $(\leq 17.2 \%)$. Addition of $250 \mu \mathrm{M}$ BA pool had no effect on cell viability. Addition of CsA $(10 \mu \mathrm{M})$ to the FFA titration in either the presence or absence of BA led to no changes in cell viability (Fig. 6A, Table 3). Increasing the FFA concentration in the presence of Trog $(100 \mu \mathrm{M})$ and in the absence of BA slightly decreased the $\mathrm{TC}_{50}$ from 

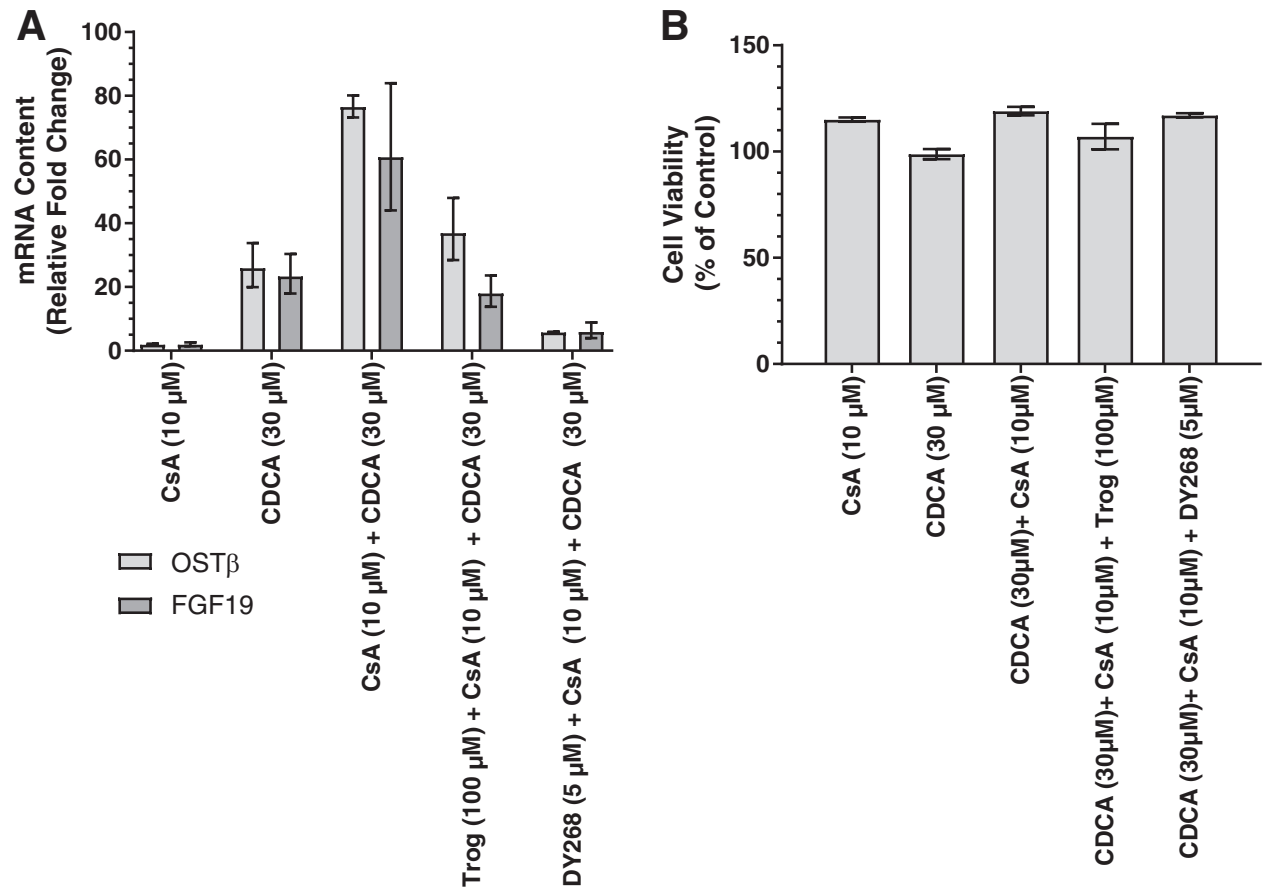

FIG. 4. (A, B) FXR Antagonism by Trog reduces basolateral efflux compensatory mechanism in SCHH. (A) Disruption of FXR activation disrupts the BA homeostasis mechanism. SCHH were established and treated as described under Materials and Methods. SCHH were treated for 24 hours with the CsA $(10 \mu \mathrm{M}$, BSEP inhibitor), CDCA (30 $\mu \mathrm{M}$, FXR agonist), CsA $(10 \mu \mathrm{M})+$ CDCA $(30 \mu \mathrm{M})$, CsA $(10 \mu \mathrm{M})+\operatorname{CDCA}(30 \mu \mathrm{M})+\operatorname{Trog}(100 \mu \mathrm{M})$, or CsA $(10 \mu \mathrm{M})+\mathrm{CDCA}(30 \mu \mathrm{M})+\mathrm{DY} 268$ $(5 \mu \mathrm{M})$. DY268 is a specific FXR antagonist used to confirm the effects of Trog. Synergistic increases in FXR target genes, $O S T \beta$ and FGF19, mRNA content were observed in SCHH co-treated with CsA $(10 \mu \mathrm{M})$ and CDCA (30 $\mu \mathrm{M})$. The synergistic response of OST $\beta$ and FGF19 gene expression was removed in the presence of Trog (100 $\mu$ M) or DY268 $(5 \mu \mathrm{M})$. Values represent the RQ mean, and error bars represent 95\% confidence intervals. (B) Cell viability was not significantly (Dunnett's; $p$-value $\geq 0.05$ ) reduced under any of the conditions evaluated suggesting that reduced gene expression in the presence of Trog or DY268 was not the result of cytotoxicity. BA, bile acid.

$\geq 1.0$ to $0.824 \mathrm{mM}$ (Fig. 6B, Table 3 ). Increasing the FFA concentrations in the presence of Trog $(100 \mu \mathrm{M})$ and a BA pool $(250 \mu \mathrm{M})$ resulted in a marked decrease in cell viability, reducing the $\mathrm{TC}_{50} \geq 2.1$-fold from $\geq 1.0$ to 0.48 (Fig. 6B, Table 3) suggesting that FFAs sensitize hepatocytes to BAinduced toxicity resulting from Trog exposure.

\section{Assessing FXR activation under sensitization conditions}

The potential of CsA and Trog to activate FXR was evaluated under sensitization conditions (e.g., BA pool+FFA). Twelve hours of exposure to a $250 \mu \mathrm{M}$ BA pool alone increased FGF19 and OST $\beta$ mRNA content 55.3-fold and 3.35-fold, respectively, in SCHH consistent with FXR activation (Fig. 7A, B). Synergistic increases of FGF19 and OST $\beta$ mRNA content of 205-fold and 27.5-fold, respectively, were observed in $\mathrm{SCHH}$ treated with $\mathrm{CsA}+250 \mu \mathrm{M}$ BA pool consistent with our previous results. In the presence of $1 \mathrm{mM}$ FFA, additional synergistic increases of FGF19 (2104-fold) and OST $\beta$ (27.8-fold) mRNA content were observed in SCHH treated with $250 \mu \mathrm{M}$ BA pool in the absence or presence of CsA. Trog $(100 \mu \mathrm{M})$ exposure markedly reduced $F G F 19$ and $O S T \beta$ mRNA content $\geq 95 \%$ and $\geq 74 \%$, respectively, in $\mathrm{SCHH}$ cultured with $250 \mu \mathrm{M}$ BA pool in the absence or presence of FFAs. Similar reductions in $F G F 19(\geq 99 \%)$ and OST $\beta(\geq 91 \%)$ were observed in SCHH treated with the potent FXR antagonist, DY268, cultured with $250 \mu \mathrm{M}$ BA pool in the absence or presence of FFAs. Again, these data were consistent with our previous results.

\section{Measuring ER stress and toxicity under sensitization conditions}

ER stress has been implicated in BA-induced (e.g., cholestatic) hepatotoxicity as the initiating step resulting in cell death. ${ }^{29,31}$ CHOP is a key component in the ER stressmediated cell death pathways. ${ }^{29-31}$ High concentrations of BA have been shown to induce $C H O P$ in isolated wild-type mice hepatocytes resulting in increased cell death, whereas cell death and liver fibrosis were attenuated in $C H O P$-knockout mice hepatocytes. ${ }^{31}$ Therefore, we evaluated the ER stress biomarker, CHOP, following 12 hours of exposure to CsA $(10 \mu \mathrm{M})$, Trog $(100 \mu \mathrm{M})$, or DY268 $(5 \mu \mathrm{M})$ under sensitization conditions (e.g., $250 \mu \mathrm{M}$ BA pool +1 mM FFA). CHOP mRNA content was induced $\leq 2.0$-fold above solvent control in $\mathrm{SCHH}$ treated with CsA $(10 \mu \mathrm{M})$ or DY268 $(5 \mu \mathrm{M})$ in the absence or presence of BA pool or BA pool+FFA (Fig. 8A). Following 12 hours of exposure, Trog $(100 \mu \mathrm{M})$ treatment induced CHOP mRNA content 2.89-fold above solvent control in $\mathrm{SCHH}$ cultured in the presence of FFAs. CHOP mRNA content was further increased to 7.1-fold above solvent control in SCHH treated with Trog $(100 \mu \mathrm{M})$ in the presence of BA pool + FFA. 

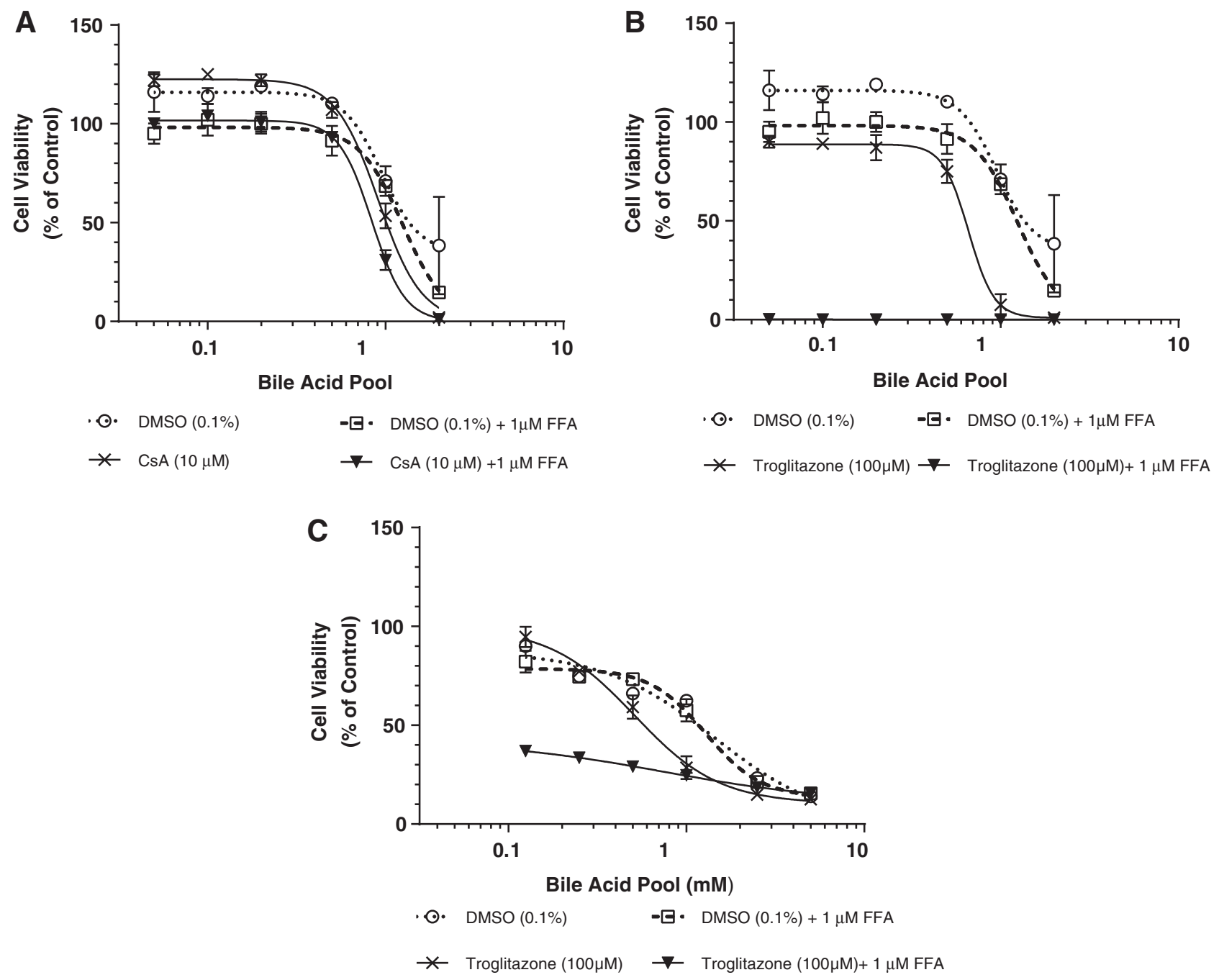

FIG. 5. (A-C) Measuring BA mediated hepatotoxicity. BA-dependent hepatotoxicity was evaluated in SCHH for 24 hours with increased exposure to a BA pool in the absence and presence of CsA $(10 \mu \mathrm{M})$, Trog $(100 \mu \mathrm{M}), \mathrm{CsA}(10 \mu \mathrm{M})+1 \mathrm{mM}$ FFA, or Trog $(100 \mu \mathrm{M})+1 \mathrm{mM}$ FFA. SCHH were seeded into 96-well plate, cultured, and treated as described in the Materials and Methods section. ATP content was utilized to assess cell viability following the exposure period. (A) In the absence of FFA, no effect on BA $\mathrm{TC}_{50}$ values was observed following CsA exposure. In the presence of FFAs, CsA exposure slightly reduced $\mathrm{BA} \mathrm{TC}_{50}$ values $\leq 30 \%$ from solvent control. (B, C) BA TC 50 values were reduced 1.4 to 2.7-fold lower than solvent control following Trog exposure across both SCHH lots. Addition of FFAs considerably increased the hepatocyte susceptibility to Trog induced BA-dependent toxicity in both SCHH preparations. BA toxicity potency was not increased in the presence of FFA in either SCHH donor. FFA, free fatty acid.

Table 2. Estimated Bile Acid TC T0 $_{5}$ Values

\begin{tabular}{lcccc}
\hline & \multicolumn{2}{c}{ FEA } & & \multicolumn{2}{c}{ Hum16081 } \\
\cline { 2 - 4 } Treatment + BA titration & $T C_{50}(m M)$ & $R^{2}$ & $T C_{50}(m M)$ & $R^{2}$ \\
\hline DMSO $(0.1 \%)$ & 0.95 & 0.91 & 1.4 & 0.96 \\
DMSO $(0.1 \%)+1$ mM FFA & 1.2 & 0.97 & 1.3 & ND \\
CsA $(10 \mu \mathrm{M})$ & 0.91 & 0.99 & ND & ND \\
CsA $(10 \mu \mathrm{M})+1 \mathrm{mM}$ FFA & 0.84 & 0.99 & 0.51 & 0.98 \\
Troglitazone $(100 \mu \mathrm{M})$ & 0.66 & 0.99 & $<0.125$ & ND \\
Troglitazone $(100 \mu \mathrm{M})+1$ mM FFA & $<0.05$ & ND &
\end{tabular}

DMSO, dimethyl sulfoxide; FFA, free fatty acid; ND, not determinable. 

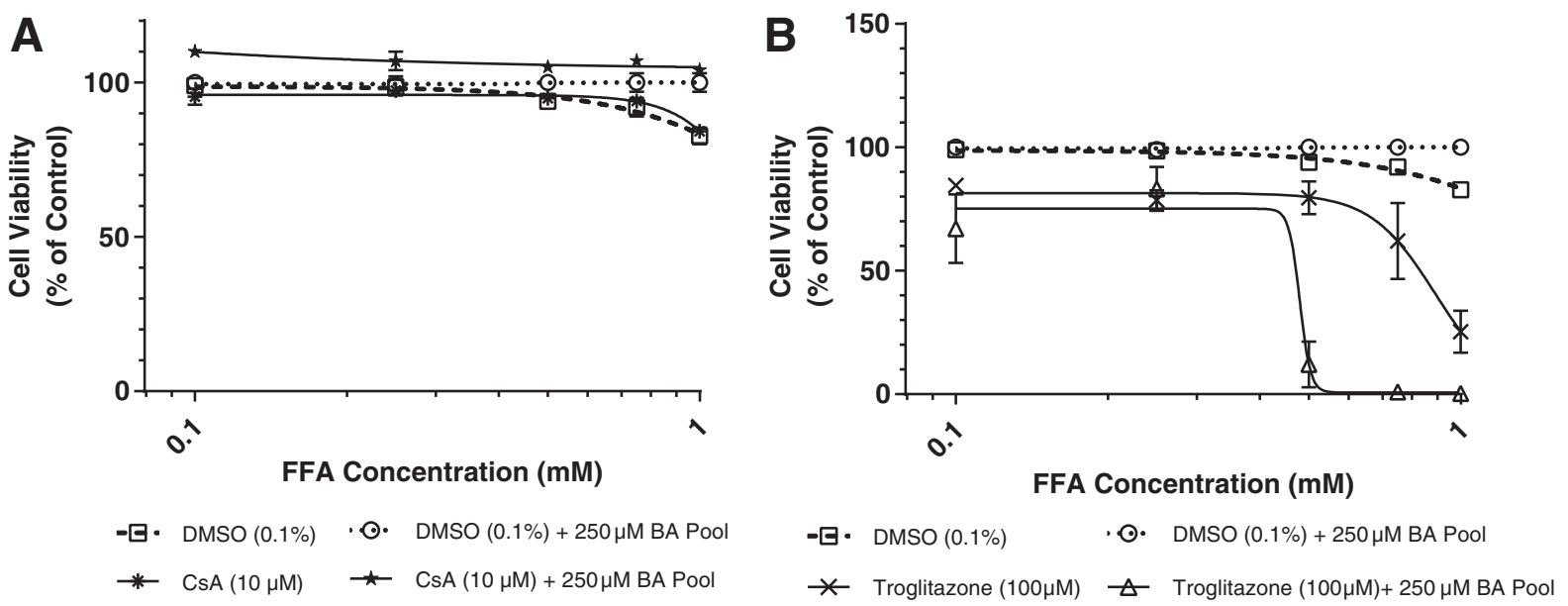

FIG. 6. (A, B) Measuring FFA mediated hepatotoxicity. FFA-dependent hepatotoxicity was evaluated in SCHH for 24 hours with increased exposure to FFAs in the absence and presence of CsA $(10 \mu \mathrm{M})$, Trog $(100 \mu \mathrm{M}), \operatorname{CsA}(10 \mu \mathrm{M})+250$ $\mu \mathrm{M}$ BA pool, or Trog $(100 \mu \mathrm{M})+250 \mu \mathrm{M}$ BA pool. SCHH were seeded into 96-well plate, cultured, and treated as described in the Materials and Methods section. ATP content was utilized to assess cell viability following the exposure period. (A) CsA exposure resulted in no changes in cell viability in SCHH across increasing concentrations of FFA in the absence or presence of BA pool. (B) Increasing the FFA concentration in the presence of Trog and in the absence of BA pool slightly increased the FFA toxicity potency $\geq 1$.12-fold greater than solvent control. However in the presence of BA pool, Trog exposure markedly increased the FFA toxicity potency $\geq 2$.1-fold greater than solvent control. FFA toxicity potency was not increased in the presence of the BA pool.

In parallel, LDH leakage was evaluated in cell culture media from the same hepatocyte cultures following 12 hours of exposure to treatments. No statistical significant increases (Dunnett's; $p$-value $\geq 0.89$ ) in LDH leakage were observed with CsA $(10 \mu \mathrm{M})$ or DY268 $(5 \mu \mathrm{M})$ treatments in absence or presence of BA pool or BA pool+FFA (Fig. 8B). LDH leakage was only significantly (Dunnett's; $p$-value $\leq 0.0001$ ) increased in SCHH treated with $\operatorname{Trog}(100 \mu \mathrm{M})$ in the presence of BA pool+FFA culture conditions. These results were consistent with marked induction of $\mathrm{CHOP}$ observed under the same conditions suggesting Trog treatment in the presence of a BA pool and FFA induced ER stress resulting in BA-induced (e.g., cholestatic) hepatocyte injury.

\section{Discussion}

Multiple publications have focused on the connection of BSEP inhibition and cholestatic (BA-dependent) DILI. ${ }^{8,9,17-19}$ However, in vitro BSEP inhibition potency values derived from vesicle studies do not accurately predict in vivo DILI incidence. ${ }^{17-19,35}$ BSEP plays an important role in the $\mathrm{Cl}_{\text {Biliary }}$ of $\mathrm{BA}$; however, the assumption that BSEP inhibition is the only

Table 3. Estimated Free Fatty Acid TC 50 Values

\begin{tabular}{lcc}
\hline & \multicolumn{3}{c}{$F E A$} \\
\cline { 2 - 3 } Treatment $+F F$ A titration & $T C_{50}(m M)^{l}$ & $R^{2}$ \\
\hline DMSO $(0.1 \%)$ & $>1$ & 0.97 \\
DMSO $(0.1 \%)+250 \mu \mathrm{M}$ BA pool & $>1$ & 0.38 \\
CsA $(10 \mu \mathrm{M})$ & $>1$ & 0.88 \\
CsA $(10 \mu \mathrm{M})+250 \mu \mathrm{M}$ BA pool & 0.89 & 0.46 \\
Troglitazone $(100 \mu \mathrm{M})$ & 0.89 \\
Troglitazone $(100 \mu \mathrm{M})+250 \mu \mathrm{M}$ BA Pool & 0.48 & 0.94 \\
\hline
\end{tabular}

factor causing cholestatic DILI is likely an oversimplification. BAs act as signaling molecules to prevent liver injury by activating the BA compensatory mechanism (e.g., FXR). The adverse outcome pathway, a more comprehensive or holistic approach, proposed by Vinken suggests that a molecular interaction (e.g., BSEP inhibition) initiates a compensatory mechanism, decreasing BA synthesis, and shunting BA to alternative handling pathways which decrease the potential for liver injury. ${ }^{36}$ This concept of a compensatory mechanism "triggered" by some initiating event has been well established in the literature. ${ }^{35,37,38}$ However, the "link" between BSEP inhibition and FXR activation through increased ICCs of endogenous BA has not been demonstrated until this present work.

Two potent BSEP inhibitors, CsA and Trog, were used to determine the activation of the compensatory mechanism in $\mathrm{SCHH}$. Although Trog has BSEP inhibition properties, its sulfated metabolite which is formed and accumulates intracellularly in SCHH is a more potent BSEP inhibitor. ${ }^{39}$ Under optimal conditions, SCHH repolarize and form networks of bile canaliculi-like structures and reestablish vectorial flow of $\mathrm{BA}^{40,41}$ while maintaining other mature hepatocyte functions, including nuclear receptor signaling and metabolism. ${ }^{42}$ These are necessary biological processes involved in BA homeostasis that an appropriate model system must support to prospectively evaluate a new chemical entity's (NCE) cholestatic DILI potential. In SCHH, exposure to either CsA or Trog reduced the biliary excretion (BEI), $\mathrm{Cl}_{\text {Biliary }}$, and total accumulation of an exogenously administered BA ( $\mathrm{d}_{8}$-TCA). Both CsA and Trog inhibited the BSEP mediated efflux (BEI) of $\mathrm{d}_{8}$-TCA with CsA being more potent than Trog. Both compounds inhibited uptake of $\mathrm{d}_{8}$-TCA to a similar extent. The BEI of BA has been shown to be independent of effects on uptake of BA. Although basolateral efflux only accounts for $\sim 25 \%$ of BA efflux in SCHH under normal conditions, inhibition of basolateral efflux of BA would lead to 

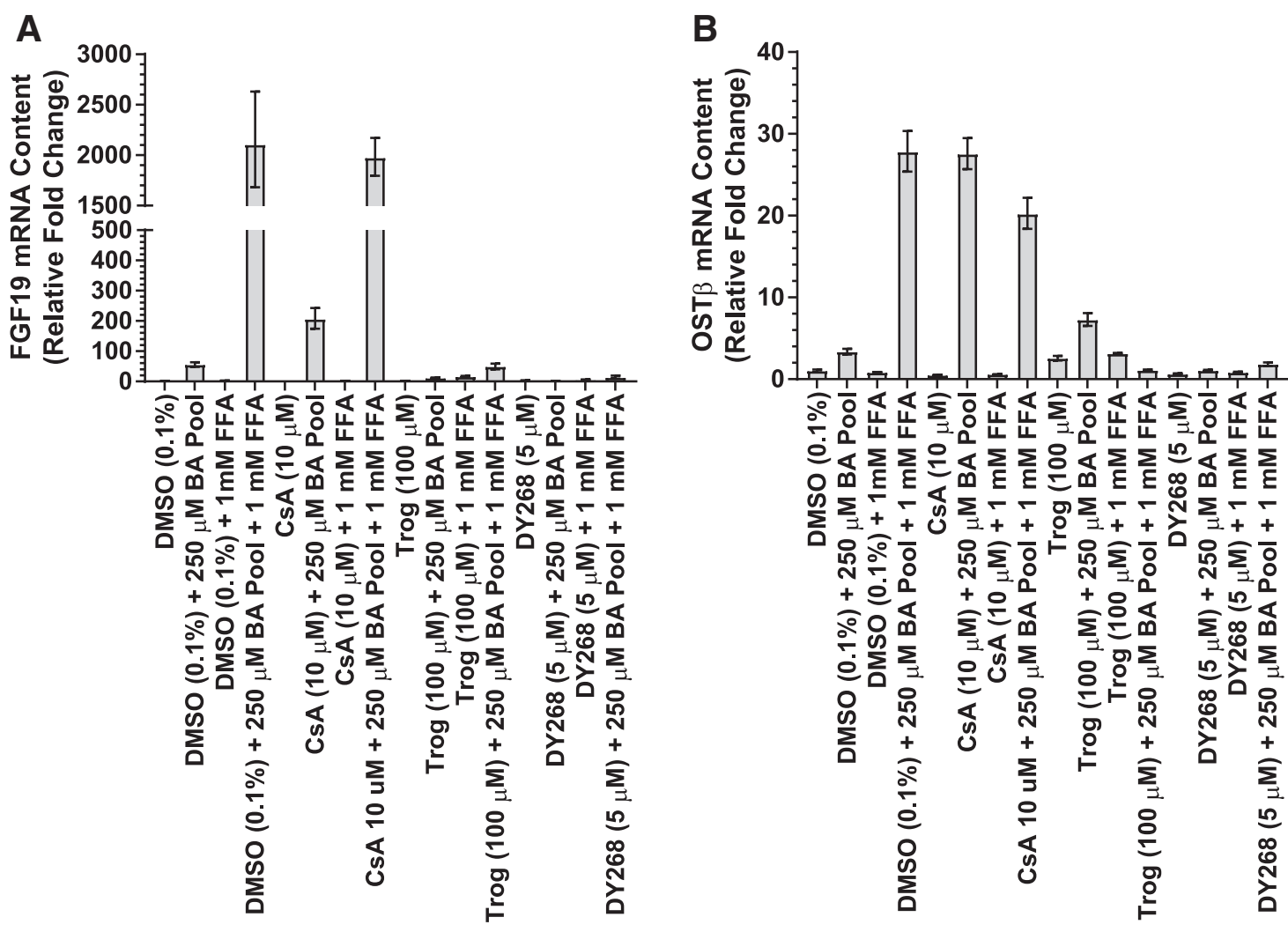

FIG. 7. (A, B) Assessing FXR activation under sensitization conditions. Trog exposure disrupts FXR activation under sensitization conditions (e.g., BA pool +FFA). SCHH were established and treated as described under Materials and Methods. SCHH were treated for 12 hours with the CsA $(10 \mu \mathrm{M})$, Trog $(100 \mu \mathrm{M})$, or DY268 $(5 \mu \mathrm{M})$ in the absence and presence of $250 \mu \mathrm{M}$ BA pool, $1 \mathrm{mM}$ FFA, or BA pool + FFA. DY268 is a specific FXR antagonist used to confirm inhibition of FXR activation. Trog $(100 \mu \mathrm{M})$ exposure markedly reduced (A) FGF19 and (B) OST $\beta$ mRNA content $\geq 95 \%$ and $\geq 74 \%$, respectively, in SCHH cultured with $250 \mu \mathrm{M}$ BA pool in the absence or presence of FFAs. Similar reductions in FGF19 $(\geq 99 \%)$ and OST $(\geq 91 \%)$ were observed in SCHH treated with the potent FXR antagonist, DY268, under the same culture conditions. Values represent the RQ mean, and error bars represent 95\% confidence intervals.

increases in the biliary excretion of BA. Therefore, inhibition of basolateral efflux would tend to decrease the observed effect on the BEI. ${ }^{43}$ In contrast, induction of basolateral efflux could lead to a decrease in the BEI; however, the exposure time is not consistent with induction of protein synthesis. $\mathrm{Cl}_{\text {Biliary }}$, a function of uptake and efflux mechanisms, was also decreased by both compounds, with CsA having a greater effect. These results were consistent with previous studies conducted in $\mathrm{SCHH} .33,34$

The primary human toxicities associated with CsA therapy are nephrotoxicity and neurotoxicity, not liver toxicity, and they have relatively low incidence of occurrence. ${ }^{20,44}$ In contrast, the clinical evidence regarding Trog toxicity estimates that the incidence of liver injury can be as high as 1:1000 patients and clearly indicates that Trog causes hepatocellular liver injury. ${ }^{20}$ The sharp contrast in clinical liver injury incidence between these two potent BSEP inhibitors suggests that in addition to BSEP inhibition other process may be involved.

Induction of the basolateral BA efflux transporter monomer OST $\beta$ and the transcription factor FGF19 by CDCA exposure was observed and was consistent with an FXRdependent mechanism reported to control the expression of these genes. ${ }^{15,16,23,24}$ Induction of $O S T \beta$ and FGF19 mRNA content in SCHH treated with CsA was similar in magnitude compared to CDCA treatment following 72 hours. Cotreatment of CDCA with increasing concentrations of CsA resulted in a synergistic induction of OST $\beta$ and FGF19 mRNA content in SCHH. These results suggested that FXR activation occurs following treatment with $\mathrm{CsA}$ and with cotreatments of CDCA and CsA. Given the observed synergistic effects, our data suggested that FXR activation occurred indirectly through increased ICCs of BA due to inhibition of BSEP. SCHH were then exposed to CsA, and the hepatobiliary disposition of an endogenous BA (GCA) was monitored over time using B-CLEAR technology. The biliary excretion of endogenous GCA was reduced in a time-dependent manner reaching statistical significance after 10 minutes of exposure; this resulted in a concomitant increase in the ICC of GCA. In parallel experiments with CsA using these same experimental conditions and time points, the mRNA expression of the FXR target genes, FGF19 and OST $\beta$, was monitored. Although OST $\beta$ was not induced, increases in FGF19 mRNA content, the more sensitive FXR target gene, and ICC GCA mirrored each other following treatment with CsA. The lack of $O S T \beta$ induction under these conditions suggested that ICC of BA did not rise to sufficient levels to activate additional BA efflux following 12 hours of CsA exposure in the absence 

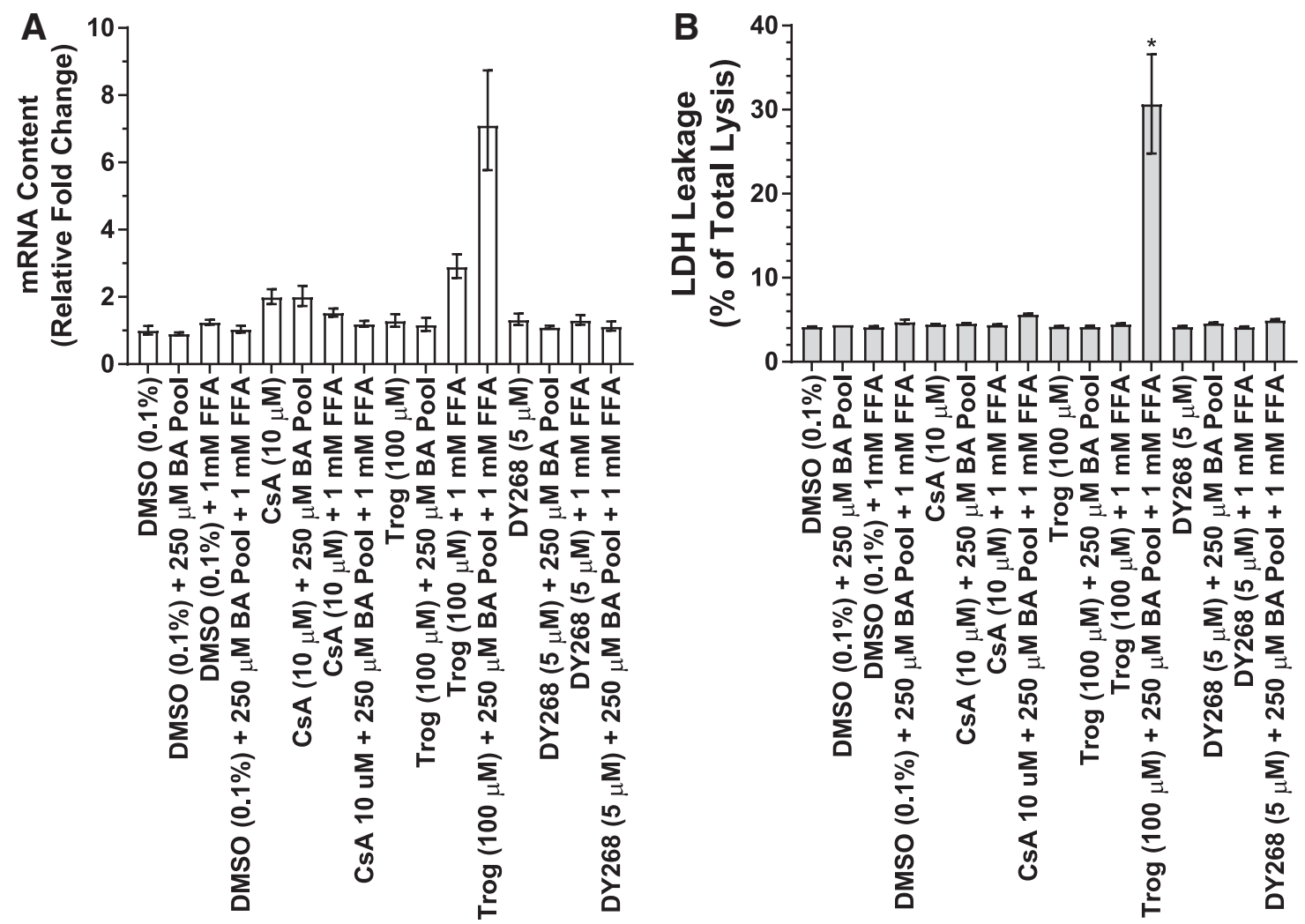

FIG. 8. (A, B) Measuring ER stress and toxicity under sensitization conditions. CHOP mRNA content was evaluated as a biomarker of ER stress. SCHH were established and treated as described under Materials and Methods. SCHH were treated for 12 hours with the CsA $(10 \mu \mathrm{M})$, Trog $(100 \mu \mathrm{M})$, or DY268 $(5 \mu \mathrm{M})$ in the absence and presence of $250 \mu \mathrm{M}$ BA pool, $1 \mathrm{mM}$ FFAs, or BA pool + FFA. (A) Trog exposure increased CHOP mRNA content 7.1-fold greater than solvent control in SCHH cultured with BA pool + FFA. CHOP mRNA content was induced $\leq 2.89$-fold above solvent control across all other conditions assessed. Values represent the RQ mean, and error bars represent 95\% confidence intervals. (B) Trog and not CsA exposure significantly increased LDH in SCHH under sensitization conditions ( $p$-value $\leq 0.0001$ ). C/EBP, CCAAT/enhancerbinding protein; $\mathrm{CHOP}, \mathrm{C} / \mathrm{EBP}$ homologous protein; $\mathrm{LDH}$, lactate dehydrogenase.

of exogenously applied BA. However, the $F G F 19$ response establishes, for the first time, a direct "link" among BSEP inhibition, increased ICC of endogenous BA, and FXR activation. In addition, activation of FXR will also increase BSEP expression, but that increase is not relevant if a potent BSEP inhibitor is present. Activation of this BA compensatory mechanism by BSEP inhibition may explain the weak concordance between BSEP inhibition potency and cholestatic DILI incidence. Many compounds may inhibit BSEP; however, the hepatocyte may be able to compensate for the resulting increase in the ICC of BA through activation of FXR and an increase in the basolateral efflux. This phenomenon is consistent with clinical observations showing that increases in circulating BA are not always associated with DILI. ${ }^{45}$

The importance of FXR regulation and the BA compensatory mechanism was evaluated following exposure to CsA, Trog, and DY268, a potent FXR antagonist. In SCHH, cotreatment of CsA and CDCA resulted in synergistic induction responses of $F G F 19$ and $O S T \beta$ mRNA content. In contrast, Trog $(100 \mu \mathrm{M})$ exposure decreased the synergistic induction response of FGF19 and OST $\beta$ mRNA content observed following co-treatment with CDCA and CsA by $70 \%$ and $52 \%$, respectively. Furthermore, treatment with a combination of
CDCA, CsA, and DY268, a novel and potent FXR antagonist, ${ }^{26}$ resulted in a $\geq 91 \%$ decrease in the FGF19 and OST $\beta$ mRNA induction response. Taken together, these results suggested that Trog $(100 \mu \mathrm{M})$ antagonized FXR preventing the hepatocyte from responding to increases in the ICC of BA. These results were consistent with reports of FXR antagonism $^{46}$ and accounts of Trog having weak FXR antagonist properties. $^{25}$

Although Ogimura et al. ${ }^{27}$ attributed all toxicity observed in sandwich-cultured rat hepatocytes (SCRH) to inhibition of BSEP, they demonstrated a novel strategy of applying an exogenous human BA pool to SCRH to evaluate cholestatic hepatotoxicity of NCEs. Hepatocytes in vitro require a BA challenge to fully evaluate the function of the BA homeostatic mechanisms. Greater than $95 \%$ of secreted BA following a meal are reabsorbed in vivo from the ileum into the portal vein ${ }^{5}$; thus, the in vivo BA portal vein concentrations are dynamic and have been reported to increase $>3$-fold between fasting and postprandial states. ${ }^{47}$ In addition, FFAs have been reported to sensitize hepatocytes to BA-induced cytotoxicity. $^{28}$ Lipid accumulation and cholestasis (e.g. BA accumulation) activate similar death pathways. ${ }^{6,28-31}$ This observation was evaluated in $\mathrm{SCHH}$ by determining the effect of CsA and Trog on hepatocyte viability across 
culture conditions with varying BA pool concentrations in the absence and presence of FFAs. Trog treatment increased the BA toxicity potency $1.4-$ to 2.7 -fold greater than solvent control across two donors. In the presence of FFAs, BA toxicity potency was markedly increased $\geq 10$ to 24 -fold greater than solvent control across both donors following Trog exposure. In contrast, $\mathrm{BA} \mathrm{TC}_{50}$ values were unchanged and only slightly reduced $(\leq 30 \%)$ following CsA treatment in the absence and presence of FFAs, respectively. These results suggested that Trog but not CsA reduced cell viability in a BA-dependent manner, and FFAs dramatically increased the hepatocyte susceptibility to Trog induced BA-dependent toxicity. In FFA titration experiments, Trog treatment but not CsA reduced FFA $\mathrm{TC}_{50}$ values in BA-dependent manner consistent with observations from BA titration experiments.

Under these sensitization conditions (BA pool + FFA), exposure to Trog and DY268, a potent FXR antagonist, reduced BA-dependent increases of the FXR target genes, FGF19 $(\geq 95 \%)$ and OST $\beta(\geq 74 \%)$. In contrast, CsA treatment did not affect the BA-dependent increases observed in $F G F 19$ and $O S T \beta$ mRNA content under the same conditions. Taken together, these results were consistent with previous results and confirmed that Trog and not CsA inhibits FXR activation.

ER stress leading to cell death has also been reported as a possible mechanism for BA-induced (e.g., cholestatic) hepatotoxicity. ${ }^{29,31}$ Blocking the BA homeostatic mechanism through inhibition of BSEP and FXR antagonism could increase ER stress initiating the programmed cell death cascades. Under sensitization conditions (BA pool + FFA),
Trog but not CsA treatment significantly induced $\mathrm{CHOP}$ mRNA content, a key marker of ER stress and early initiator of cell death. ${ }^{29-31}$ Concomitant increases in LDH leakage were observed under sensitization conditions with Trog but not CsA treatment. These results suggested Trog but not CsA treatment in the presence of a BA pool and FFAs induced ER stress resulting in BA-induced (e.g., cholestatic) hepatocyte injury. BA ICC determinations (data not shown), normalized for ATP content, indicated that BAs increased $\sim 130 \%$ and $\sim 900 \%$ of solvent control in SCHH under sensitization conditions following exposure to CsA or Trog, respectively. Following exposure to a BSEP inhibitor (e.g., CsA), hepatocytes were able to compensate by increasing basolateral efflux to maintain a subtoxic ICC of BAs. However, in the case of a compound possessing both BSEP and FXR antagonist properties (e.g., Trog), the BA homeostatic mechanism was blocked and caused the ICC of BA to increase rapidly which led to cell death. These conclusions were consistent with substantial clinical evidence establishing a causal link between Trog exposure and DILI ${ }^{20}$ and lack thereof with CsA therapy.

Under this new paradigm (Fig. 9), compounds that inhibit BSEP alone would not have a high potential for BA-induced hepatotoxicity. However, if those same compounds also antagonize FXR and prevent the hepatocyte from reducing ICC of BA, then those compounds would increase the potential for cholestatic (e.g., BA induced) hepatotoxicity. Guo et al. ${ }^{48}$ linked increases in the mRNA of OST $\alpha / \beta$ resulting from increased ICC of BA to increases in the basolateral clearance of BA. In the presence of increased ICC of BA,
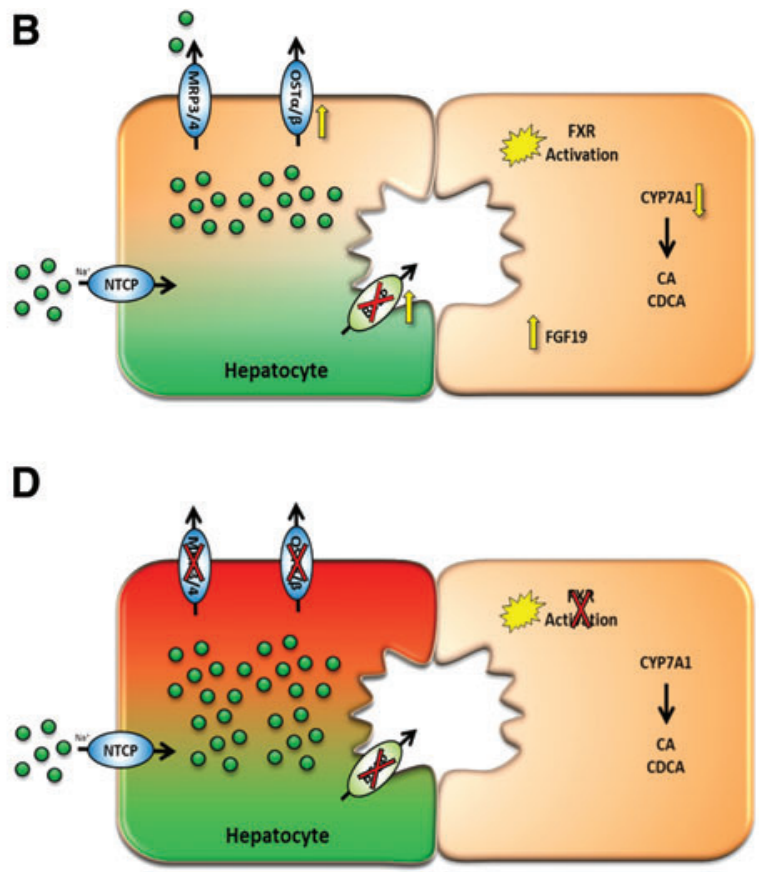

FIG. 9. Bile acid basolateral efflux prevents cholestatic DILI. Basolateral efflux mechanism (OST) prevents cholestatic DILI. (A) Normal BA flow. (B) Inhibition of canalicular BA efflux (BSEP) results in transient increase in the ICC of endogenous BA activating FXR. (C) Basolateral efflux (OST) becomes active through FXR activation lowering the ICC of endogenous BA to prevent BA toxicity. Once ICC of BA returns to normal and BSEP inhibition is removed, compensatory mechanism dissipates allowing BA flow to return to native state. (D) Cholestatic DILI: Hepatic ICC of BA rise to toxic levels as a result of BSEP inhibition plus FXR antagonism (e.g., Trog), or basolateral efflux inhibition (OST/MRP3/4), or all of the above. DILI, drug induced liver injury; OST, organic solute and steroid transporter. Color images available online at www.liebertpub.com/aivt 
basolateral efflux clearance becomes a major elimination pathway. This suggests that inhibition of basolateral efflux clearance could be an additional mechanism for cholestatic hepatotoxicity. Inhibition of multiple efflux pathways (i.e., BSEP, OST $\alpha / \beta$, and MRP3/4) would increase the BA concentration inside the hepatocyte and, even if FXR is activated, still result in lethal concentrations of BAs. Recently, Malinen et al. demonstrated that Trog sulfate was an inhibitor of OST $\alpha / \beta$ mediated transport of taurocholate uptake, perhaps providing another possible mechanism for Trog hepatotoxicity. ${ }^{49}$

Addition of FFAs in the presence of a BA pool improved the detection of BA-dependent hepatotoxicity by Trog exposure. These results support the reports linking lipid accumulation and BA-induced hepatocyte injury suggesting that certain human populations (e.g., nonalcoholic fatty liver disease) may be more at risk for BA-dependent DILI. ${ }^{28}$

The hepatocyte compensatory mechanism helps to maintain appropriate BA ICC and plays an important role in protecting the hepatocyte from BA hepatotoxicity. ${ }^{5,14,15}$ This compensatory mechanism may explain the disconnect between in vitro BSEP inhibition potency determinations and accurate prediction of in vivo BA-dependent DILI incidence. In the present study, CsA and Trog were demonstrated to inhibit biliary efflux of BA; however, Trog also interfered with the hepatocyte's compensatory mechanism (FXR antagonism and inhibition of basolateral efflux clearance), resulting in hepatotoxicity which is consistent with clinical evidence of hepatocellular damage following Trog therapy. ${ }^{20}$ Whole cell models that integrate multiple processes (inhibition, induction, and metabolism) could be extremely useful in not only assessing BSEP inhibition but also accurately predicting BA-dependent DILI.

\section{Acknowledgments}

The authors thank Dr. James McKim, Jr. for his assistance in the writing of this article. The laboratory research was funded by BioIVT.

\section{Author Disclosure Statement}

Jackson, Black, Freeman, St. Claire III, and Brouwer are employees of BioIVT. McKim is the founder of Iontox, LLC, Kalamazoo, MI and has nothing to disclose.

\section{References}

1. Abboud G, Kaplowitz N. Drug-induced liver injury. Drug Saf 2007:30;277-294.

2. Food Drug Administration. Guidance for Industry: DrugInduced Liver Injury: Premarketing Clinical Evaluation. Silver Spring, MD: Food and Drug Administration; 2009.

3. Maddrey WC. Drug-induced hepatotoxicity. J Clin Gastroenterol 2005:39;S83-S89.

4. Guicciardi ME, Gores GJ. Bile acid-mediated hepatocyte apoptosis and cholestatic liver disease. Digest Liver Dis 2002:34;387-392.

5. Chiang JYL. Bile acids: Regulation of synthesis. J Lipid Res 2009:50;1955-1966.

6. Wanwei L, Menggang L, Long C, et al. Bile acids induced cell necropotosis. Cytol Histol 2014:S4;1-4.
7. Gerloff T, Stieger B, Hagenbuch B, et al. The sister of Pglycoprotein represents the canalicular bile salt export pump of mammalian liver. J Biol Chem 1998:273;10046-10050.

8. Morgan RE, Trauner M, van Staden CJ, et al. Interference with bile salt export pump function is a susceptibility factor for human liver injury in drug development. Toxicol Sci 2010:118;485-500.

9. Morgan RE, van Staden CJ, Chen Y, et al. A multifactorial approach to hepatobiliary transporter assessment enables improved therapeutic compound development. Toxicol Sci 2013:136;216-241.

10. Makishima M, Okamoto AY, Repa JJ, et al. Identification of a nuclear receptor for bile acids. Science 1999:284;3621365.

11. Parks DJ, Blanchard SG, Bledsoe RK, et al. Bile acids; Natural ligands for an orphan nuclear receptor. Science 1999: 284;1365-1368.

12. Schuetz EG, Strom S, Yasuda K, et al. Disrupted bile acid homeostasis reveals an unexpected interaction among nuclear hormone receptors, transporters, and cytochrome P450. J Biol Chem 2001:276;39411-39418.

13. Del Castillo-Olivares A, Campos JA, Pandak WM, et al. Role of FTF/LRH-1 on bile acid biosynthesis. A known nuclear receptor activator that can act as a suppressor of bile acid biosynthesis. J Biol Chem 2004:279;16813-16821.

14. Boyer JL, Trauner M, Mennone A, et al. Upregulation of a basolateral FXR-dependent bile acid efflux transporter OST $\alpha-$ OST $\beta$ in cholestasis in humans and rodents. Am J Physiol Gastrointest Liver Physiol 2006:290;G1124-G1130.

15. Jackson JP, Freeman KM, Friley WW, et al. Basolateral efflux transporters: A potentially important pathway for the prevention of cholestatic hepatotoxicity. Appl In Vitro Toxicol 2016:2;207-216.

16. Zhang Y, Jackson JP, St. Claire III RL, et al. Obeticholic acid, a selective Farnesoid $\mathrm{X}$ receptor agonist, regulates bile acid homeostasis in sandwich-cultured human hepatocytes. Pharmacol Res Perspect 2017:5;1-11.

17. Kis E, Ioja E, Rajnai Z, et al. BSEP inhibition-In vitro screens to assess cholestatic potential of drugs. Toxicol In Vitro 2012:26;1294-1299.

18. Dawson S, Stahl S, Paul N, et al. In vitro inhibition of the bile salt export pump correlates with risk of cholestatic drug-induced liver injury in humans. Drug Metab Dispos 2012:40;130-138.

19. Pedersen JM, Matsson P, Begstrom CAS, et al. Early Identification of clinically relevant drug interactions with the human bile salt export pump. Toxicol Sci 2013:136;328-343.

20. LiverTox.nih.gov (accessed March 2018).

21. Liu X, Chism JP, LeCluyse EL, et a. Correlation of biliary excretion in sandwich-cultured rat hepatocytes and in vivo in rats. Drug Metab Dispos 1999:27;637-644.

22. Ghibellini G, Vasist LS, Leslie EM, et al. In vitro-in vivo correlation of hepatobiliary drug clearance in humans. Clin Pharmacol Ther 2007:81;406-413.

23. Holt JA, Luo G, Billin AN, et al. Definition of a novel growth factor-dependent signal cascade for the suppression of bile acid biosynthesis. Genes Dev 2003:17;1581-1591.

24. Liu J, Lu H, Lu YF, et al. Potency of individual bile acids to regulate bile acid synthesis and transport genes in primary human hepatocyte cultures. Toxicol Sci 2014:141;538-546.

25. Kaimal R, Song X, Yan B, et al. Differential modulation of farnesoid $X$ receptor signaling pathway by the thiazolidinediones. J Pharmacol Exp Ther 2009:330;125-134. 
26. Yu DD, Lin W, Forman BM, et al. Identification of trisubstituted-pyrazol carboxamide analogs as novel and potent antagonists of farnesoid X receptor. Bioorg Med Chem 2014:22;2919-2938.

27. Ogimura E, Sekine S, Horie T. Bile salt export pump inhibitors are associated with bile acid-dependent drug-induced toxicity in sandwich-cultured hepatocytes. Biochem Biophys Res Commun 2011:416;313-317.

28. Pusl T, Wild N, Vennegeers T, et al. Free fatty acids sensitize hepatocytes to bile acid-induced apoptosis. Biochem Biophys Res Commun 2008, 371;441-445.

29. Perez MJ, Briz O. Bile-acid-induced cell injury and protection. World J Gastroenterol 2009:15;1677-1689.

30. Hirsova P, Ibrabim SH, Gores GJ, et al. Lipotoxic lethal and sublethal stress signaling in hepatocytes: Relevance to NASH pathogenesis. J Lipid Res 2016:57;1758-1770.

31. Tamaki N, Hatano E, Taura K, et al. CHOP deficiency attenuates cholestasis-induced liver fibrosis by reduction of hepatocyte injury. Am J Physiol Gastrointest Liver Physiol 2008: 294;G498-G505.

32. Lee JK, Brouwer KR. Determination of intracellular volume of rat and human sandwich-cultured hepatocytes. Toxicol Sci 2010:114(S);339.

33. Ansede JH, Smith WR, Perry CH, et al. An in vitro assay to assess transporter-based cholestatic hepatotoxicity using sandwich-cultured rat hepatocytes. Drug Metab Dispos 2010:38;276-280.

34. Marion TL, Leslie EM, Brouwer KLR. Use of sandwichcultured hepatocytes to evaluate impaired bile acid transport as a mechanism of drug-induced hepatotoxicity. Mol Pharm 2007:4;911-918.

35. Rodrigues DA, Lai Y, Cvijic ME, et al. Drug-induced perturbations of the bile acid pool, cholestasis, and hepatotoxicity: Mechanistic considerations beyond the direct inhibition of the bile salt export pump. Drug Metab Dispos 2014:42; $566-574$.

36. Vinken M. The adverse outcome pathway concept: A pragmatic tool in toxicology. Toxicology 2013:312;158-165.

37. Stahl S, Davies MR, Cook DI, et al. Nuclear hormone receptor-dependent regulation of hepatic transporters and their role in the adaptive response in cholestasis. Xenobiotica 2008:38;725-777.

38. Humbert L, Maubert MA, Wolf C, et al. Bile acid profiling in human biological samples: Comparison of extraction procedures and application to normal and cholestatic patients. J Chromatogr B Analyt Technol Biomed Life Sci 2012:899; 135-145.

39. Lee JK, Marion TL, Abe K, et al. Hepatobiliary disposition of troglitazone and metabolites in rat and human sandwichcultured hepatocytes: Use of monte carlo simulations to assess the impact of changes in biliary excretion on trogli- tazone sulfate accumulation. J Pharmacol Exp Ther 2010: 332;26-34.

40. Liu X, Lecluyse EL, Brouwer KR, et al. Use of Ca2+ modulation to evaluate biliary excretion in sandwich-cultured rat hepatocytes. J Pharmacol Exp Ther 2009:289;1592-1599.

41. Swift B, Pfeifer ND, Brouwer KLR. Sandwich-cultured hepatocytes: An in vitro model to evaluate hepatobiliary transporter-based drug interactions and hepatotoxicity. Drug Metab Rev 2010:42;446-471.

42. Hewitt NJ, Lechón MJG, Houston JB, et al. Primary hepatocytes: Current understanding of the regulation of metabolic enzymes and transporter proteins, and pharmaceutical practice for the use of hepatocytes in metabolism, enzyme induction, transporter, clearance, and hepatotoxicity studies. Drug Metab Rev 2007:39;159-234.

43. Yang K, Pfeifer ND, Kock K, et al. Species differences in hepatobiliary disposition of taurocholic acid in human and rat sandwich-cultured hepatocytes: Implications for drug-induced liver injury. J Pharmacol Exp Ther 2015:353;415-423.

44. Magnasco A, Rossi A, Catarsi P, et al. Cyclosporin and organ specific toxicity: Clinical aspects, pharmacogenetics and perspectives. Curr Clin Pharmacol 2008:3;166-173.

45. Ozer J, Ratner M, Shaw M, et al. The current state of serum biomarkers of hepatotoxicity. Toxicology 2008:245;194205.

46. Lu W, Cheng F, Jiang J, et al. FXR antagonism of NSAIDs contributes to drug-induced liver injury identified by systems pharmacology approach. Sci Rep 2015:5;1-10.

47. Angelin B, Bjorkhem I, Einarsson K, et al. Hepatic uptake of bile acids in man. Fasting and postprandial concentrations of individual bile acids in portal venous and systemic blood serum. J Clin Invest 1982:70;724-731.

48. Guo C, LaCerte C, Edwards JE, et al. Farnesoid X Receptor agonists obeticholic acid and chenodeoxycholic acid increase bile acid efflux in sandwich-cultured human hepatocytes: Functional evidence and mechanisms. J Pharmacol Exp Ther 2018:365;413-421.

49. Malinen M, Ali I, Bezencon J, et al. Organic solute transporter OST $\alpha / \beta$ is over-expressed in nonalcoholic steatohepatitis and modulated by drugs associated with liver injury. Am J Physiol Gastrointest Liver Physiol 2018: 314;G597-G609.

Address correspondence to: Dr. Jonathan P. Jackson BioIVT, ADME-TOX Division 2810 Meridian Parkway Suite 100

Durham, NC 27713

E-mail: jjackson@bioivt.com 